\title{
Copper-Zinc Superoxide Dismutase (SOD1) Is Released by Microglial Cells and Confers Neuroprotection against 6-OHDA Neurotoxicity
}

\author{
Elisabetta Polazzi ${ }^{a} \quad$ Ilaria Mengoni ${ }^{a}$ Marco Caprini ${ }^{b} \quad$ Emiliano Peña-Altamira ${ }^{a}$ \\ Ewelina Kurtys $^{\mathrm{a}}$ Barbara Monti $^{\mathrm{a}}$ \\ Departments of a Biology and ${ }^{b}$ Human and General Physiology, University of Bologna, Bologna, Italy
}

\section{Key Words}

Microglia $\cdot$ Conditioned medium $\cdot$ SOD1 $\cdot$

Neuroprotection - Cerebellar granule neurons •

6-Hydroxydopamine

\begin{abstract}
Microglial-neuronal interactions are essential for brain physiopathology. In this framework, recent data have changed the concept of microglia from essentially macrophagic cells to crucial elements in maintaining neuronal homeostasis and function through the release of neuroprotective molecules. Using proteomic analysis, here we identify copper-zinc superoxide dismutase (SOD1) as a protein produced and released by cultured rat primary microglia. Evidence for a neuroprotective role of microglia-derived SOD1 resulted from experiments in which primary cerebellar granule neurons (CGNs) were exposed to the dopaminergic toxin 6-hydroxydopamine (6-OHDA). Microglial conditioned medium, in which SOD1 had accumulated, protected CGNs from degeneration, and neuroprotection was abrogated by SOD1 inhibitors. These effects were replicated when exogenous SOD1 was added to a nonconditioned medium. SOD1 neuroprotective action was mediated by increased cell calcium from an external source. Further experiments demonstrated the specificity of SOD1 neuroprotection against 6-OHDA com-
\end{abstract}

\section{KARGER}

E-Mail karger@karger.ch www.karger.com/nsg (c) 2012 S. Karger AG, Basel $1424-862 X / 13 / 0212-0112 \$ 38.00 / 0$

\section{Karge}

Open access

This is an Open Access article licensed under the terms of the Creative Commons Attribution-NonCommercialNoDerivs 3.0 License (www.karger.com/OA-license), applicable to the online version of the article only. Distribution for non-commercial purposes only. pared to other types of neurotoxic challenges. SOD1, constitutively produced and released by microglia through a lysosomal secretory pathway, is identified here for the first time as an essential component of neuroprotection mediated by microglia. This novel information is relevant to stimulating further studies of microglia-mediated neuroprotection in in vivo models of neurodegenerative diseases.

Copyright $\odot 2012$ S. Karger AG, Base

\section{Introduction}

Microglia, the resident immune cells of the central nervous system, possess distinctive physiological and pathological properties, the understanding of which has considerably progressed in recent years [1-7]. Some of this research has led to the development of novel concepts in microglial function. In particular, attention has been focused on microglia-derived neuroprotection and on immunomodulation to boost the physiologic properties of these cells, thus counteracting the pathologic consequences of their excessive activation [8].

Elisabetta Polazzi and Ilaria Mengoni contributed equally to the present work. 
The neuroprotective role of microglia is exerted not only as a response to a neuropathologic threat but also in physiologic conditions. 'Quiescent' or 'dormant' microglia actually play a role in continuous surveillance of the brain microenvironment, participate in synapse remodeling and function, influence neurogenesis, and provide trophic support for the survival of neurons and maintenance of neural circuits [9-13]. This led to the idea that physiological microglial functions are exerted through the production and release of substances with neuroprotective, survival-favoring properties. Moreover, several experimental approaches have been developed to demonstrate this kind of neuroprotection, as well as to identify microglia-derived neuroprotective molecules. In vitro models based on neuron-microglia co-cultures or on neuronal exposure to microglial conditioned media (MCM) have been particularly useful. In co-culture conditions, microglia has been shown to protect neurons from nitrosative stress, metabolic impairment, and maintenance in nontrophic conditions [14-16]. A similar microglia-mediated neuroprotection has also been granted to organotypic hippocampal cultures exposed to oxygenglucose deprivation [17]. Furthermore, MCM has been shown to promote the survival of rat mesencephalic neurons [18] and protect cerebellar granule neurons (CGNs) from nontrophic conditions, including staurosporine-induced apoptosis and excitotoxicity $[16,19]$, and cortical neurons from $\beta$-amyloid toxicity [20]. Some of the molecules released by microglia have already been identified and, in some cases, a neuroprotective activity has been characterized. In the above mentioned experiments on cortical neurons [20], the MCM neuroprotective effect was attributed to the release of apolipoprotein $\mathrm{E}$ from microglia. In cultured dopaminergic mesencephalic neurons, microglia-derived plasminogen is neuroprotective through dopamine uptake [21]. In CGNs exposed to the dopaminergic toxin 6-hydroxydopamine (6-OHDA), we recently identified transforming growth factor- $\beta 2$ (TGF$\beta 2$ ) as a neuroprotective molecule released by microglia [22]. In addition to constitutively released neuroprotective factors, exposure of microglia to media conditioned by apoptotic neurons may increase their neuroprotective action [16] as demonstrated by the release of immunoregulatory and pro-survival factors, such as prostaglandin E2, NGF, and TGF- $\beta$ [23].

Here we identify for the first time $\mathrm{Cu}-\mathrm{Zn}$ superoxide dismutase (SOD1) as an effector of MCM-mediated neuroprotection. SOD1 is a particularly intriguing protein for brain pathophysiology, as mutations in its codifying gene are responsible for the familial forms of the neuro- degenerative disorder amyotrophic lateral sclerosis (ALS) [24]. We demonstrate that SOD1 is released by microglia and accumulates in culture medium. Released SOD1 contributes to the neuroprotective properties of the conditioned medium itself, with neuroprotection being reproduced by the addition of exogenous SOD1 to a nonconditioned medium. Evidence points to increased calcium levels from extracellular sources as the mediator of SOD1 action. This novel knowledge may improve our understanding of the complex relationships between neurons and microglial cells with particular reference to the mechanisms of microglia-mediated neuroprotection and to their molecular effectors.

\section{Materials and Methods}

\section{Microglial Cell Culture and MCM}

Primary cultures of microglial cells were prepared from newborn Wistar rat cerebral cortices as previously described [16]. All animal experiments were authorized by a local bioethical committee and performed in accordance with the Italian and European Community law on the use of animals for experimental purposes. Briefly, brain tissue was cleaned from meninges and trypsinized for $15 \mathrm{~min}$ at $37^{\circ} \mathrm{C}$; after mechanical dissociation, the cell suspension was washed and plated on poly-L-lysine $(10 \mu \mathrm{g} / \mathrm{ml}$; Sigma-Aldrich, St. Louis, Mo., USA)-coated flasks $\left(75 \mathrm{~cm}^{2}\right)$. Mixed glial cells were cultured for 7-8 days in Basal Medium Eagle (BME; Invitrogen, Paisley, UK) supplemented with $10 \%$ heatinactivated fetal bovine serum (Invitrogen), $2 \mathrm{~mm}$ glutamine, and $100 \mu \mathrm{M}$ gentamicin sulfate (Sigma-Aldrich). Microglial cells were harvested from mixed glial cell cultures by mechanical shacking, resuspended in serum-free BME, and plated on uncoated $40-\mathrm{mm}$ $\varnothing$ dishes at a density of $1.5 \times 10^{6}$ cells $/ 1.5 \mathrm{ml}$ medium/well. Cells were allowed to adhere for $30 \mathrm{~min}$ and were then washed to remove nonadhering cells. After 2, 24, and $48 \mathrm{~h}, \mathrm{MCM}$ was collected, filtered through $0.22-\mu \mathrm{m}$ filters, and stored at $-20^{\circ} \mathrm{C}$ until use. For the evaluation of SOD1 release, microglial cells were plated on uncoated 12-well plates at a density of $7.5 \times 10^{5}$ cells/well and stimulated with lipopolysaccharide (LPS), rat recombinant interferon- $\gamma($ IFN- $\gamma)$, or both, as well as with adenosine tryphosphate (ATP) at different concentrations (all chemicals were from Sigma-Aldrich). After $24 \mathrm{~h}$ ( $1 \mathrm{~h}$ for ATP treatment) the media were collected and then lyophilized using Microcon-YM-3 (Millipore, Billerica, Mass., USA), and the expression of SOD1 was analyzed via Western blot analysis.

\section{Microglial Transfection}

Microglial cells were transfected with the mammalian expression vector pcDNA3 (Invitrogen) containing full-length cDNA encoding wild-type or mutated (G93A) human SOD1 (pcDNA3SOD1wt/G93A), a kind gift from Prof. Angelo Poletti [25], or two different commercially available siRNA (Sigma) against SOD1, previously tested for their efficacy by the Rosetta bioinformatics system. Transfection was performed using LipofectAMINE 2000 Reagent (Invitrogen), following the manufacturer's protocol, in OptiMEM/serum-free BME (Invitrogen) without antibiotics for 
$4 \mathrm{~h}$; the medium with lipid-DNA complex was then replaced with serum-free BME. Twenty-four hours after plasmid transfection or $48 \mathrm{~h}$ following siRNA transfection, MCM were collected, cleared of contaminating cells by filtration (through $0.22-\mu \mathrm{m}$ filters) or by centrifugation $(10,000 \mathrm{~g}$ for $5 \mathrm{~min})$, and stored at $-20^{\circ} \mathrm{C}$ until use for Western blot and neuroprotection analysis on CGNs. The vector pmaxGFP ${ }^{\circledR}$ (Amaxa, Cologne, Germany) was used both as a plasmid control and as a test for transfection efficiency.

\section{CGN Cultures}

Primary cultures of CGNs were prepared from 7-day-old Wistar rats, as previously described [26]. Briefly, cells were dissociated from cerebella and plated on 96-well plates or in $40-\mathrm{mm} \varnothing$ dishes, previously coated with $10 \mu \mathrm{g} / \mathrm{ml}$ poly-L-lysine, at a density of $2 \times 10^{5}$ cells $/ \mathrm{cm}^{2}$ in BME supplemented with $10 \%$ heatinactivated fetal bovine serum (Invitrogen), $2 \mathrm{~mm}$ glutamine, 100 $\mu \mathrm{M}$ gentamicin sulfate, and $25 \mathrm{~mm} \mathrm{KCl}$ (all from Sigma-Aldrich). Sixteen hours later, $10 \mu \mathrm{M}$ cytosine arabino-furanoside (SigmaAldrich) was added to avoid glial proliferation. After 7 days in vitro, differentiated neurons were shifted to serum-free BME medium containing $25 \mathrm{mM} \mathrm{KCl}$ and treated with $20 \mu \mathrm{M}$ 6-OHDA (Sigma-Aldrich). The neuroprotective effect of MCM, as well as the one of exogenous SOD1 (Sigma-Aldrich), was tested on this in vitro model of neurotoxicity. Specific SOD inhibitors, ammonium tetrathio-molybdate and disulfiram, or the extracellular calcium-chelating agent ethylenediaminetetraacetic acid (EDTA) were examined to block the neuroprotective effect of exogenous SOD1 as well as that of microglia-secreted SOD1 present in MCM (all chemicals from Sigma-Aldrich). The possible SOD1 neuroprotection was also studied in other classical models of CGN neurotoxicity, i.e. the shift of differentiated neurons to a low potassium concentration $(5 \mathrm{mM} \mathrm{KCl})$ for $24 \mathrm{~h}$ or the chronic $(24 \mathrm{~h})$ exposure of neurons to $100 \mu \mathrm{M}$ glutamate (all from Sigma-Aldrich). Neuronal survival was analyzed using the 3-(4,5-dimethylthiazol-2-yl) 2,5-diphenyl-tetrazolium bromide (MTT; SigmaAldrich) test. To measure the neuroprotection exerted by MCM conditioned for 2, 24, and $48 \mathrm{~h}$, nucleus counting following Hoechst staining was performed as described below.

MTT Assay

The viability of CGN cultures was evaluated by thiazolyl blue (MTT) assay [27]. This method is based on conversion of the tetrazolium salt to a colored compound, a reaction that only occurs in viable cells since the chemical reaction is carried out by mitochondrial dehydrogenases. MTT (Sigma-Aldrich) was added to the culture medium to reach a final concentration of $0.1 \mathrm{mg} / \mathrm{ml}$. Following $15 \mathrm{~min}$ of incubation at $37^{\circ} \mathrm{C}$ in the dark, formed crystals were dissolved in $0.1 \mathrm{M}$ Tris- $\mathrm{HCl}$ buffer containing $5 \%$ Triton X-100 (all from Sigma-Aldrich) and the absorbance was read at $570 \mathrm{~nm}$ in a Multiplate Spectophotometric Reader (Bio-Rad Laboratories, Hercules, Calif., USA).

\section{Proteomic Analysis of MCM}

MCM were concentrated using Amicon ultra-15 (3-kDa centrifugal filter; Millipore), and albumin was removed using a SwellGel ${ }^{\circledR}$ Blue Albumin Removal Kit (Pierce, Rockford, Ill., USA) according to the manufacturer's instructions. Starting from $60 \mathrm{ml}$ (containing $700 \mu \mathrm{g}$ of total proteins) of 48-hour MCM (from $60 \times 10^{6}$ microglial cells) to reach $400 \mu \mathrm{g}$ of total proteins, samples were loaded on the gel after de-albuminization. The con- ditioned medium was concentrated and then brought to a final volume of $350 \mu \mathrm{l}$ with rehydration buffer made of $8 \mathrm{M}$ urea, $0.5 \%$ CHAPS, 18 mM DTT, 0.002\% bromophenol blue (all from SigmaAldrich), and $0.8 \%$ pH 3-10 Amersham Pharmalytes (GE Healthcare, Chalfont St. Giles, UK). The samples were loaded into a rehydration strip tray, and $18-\mathrm{cm}$ pH 3-10 NL IPG strips (GE Healthcare) were placed facing the samples and left to rehydrate for at least $12 \mathrm{~h}$ (overnight). The first dimension was run using a Multiphor III (GE Healthcare) at $50 \mu \mathrm{A}$ per strip for 9 steps until a total of $80 \mathrm{kV}$ was reached. Once the first dimension was finished, the strips were stored at $-80^{\circ} \mathrm{C}$ until needed for the second dimension. Before the second dimension, the strips were equilibrated by incubation in equilibration buffer $(6 \mathrm{M}$ urea, $75 \mathrm{mM}$ Tris-HCl pH 8.8, 29.3\% glycerol, 2\% SDS, and $0.002 \%$ bromophenol blue) first in $1 \%$ DTT for $15 \mathrm{~min}$ and then in $2.5 \%$ iodoacetamide for $15 \mathrm{~min}$. Following the equilibration, the strips were briefly washed in Laemli SDS electrophoresis buffer $(25 \mathrm{mM}$ Tris base, $192 \mathrm{~mm}$ glycine, 0.1\% SDS) (all chemicals were from SigmaAldrich). The equilibrated strips were loaded onto $15 \%$ polyacrylamide gels (Bio-Rad Laboratories) together with Bio-Rad wide-range protein standard markers. The IPG strips were overlaid with agarose sealing solution $(0.5 \%$ agarose and $0.002 \%$ bromophenol blue in Laemli SDS electrophoresis buffer, all from Sigma-Aldrich). The second dimension was performed keeping the buffer tank temperature constant at $20^{\circ} \mathrm{C}$ throughout the entire second dimension for $30 \mathrm{~min}$ at $2 \mathrm{~W}$ per gel and 5-6 h at $15 \mathrm{~W}$ per gel until the blue dye front reached the bottom of the gel.

After the second dimension was finished, gels were immediately stained in Coomassie Briliant Blue G-250 solution (10\% acetic acid, $40 \%$ methanol, $\mathrm{x} \% \mathrm{CBB}$ ) with constant shaking for $48 \mathrm{~h}$. Afterwards, the gels were left in deionized water with constant shaking until the protein spots were clearly visible. Gel images were captured using a Pharos FX (Bio-Rad) scanner at a resolution of $50 \mu \mathrm{m}$. Raw images (each sample was analyzed in three different gels) were analyzed using Proteomweaver 4.0 software (BioRad). Differentially expressed spots, with intensity significantly increased on the average map, were collected. Peptide identification was performed by the proteomics laboratory at CRBA, Center for Applied Biomedical Research at S. Orsola-Malpighi University Hospital in Bologna, Italy, by trypsin digestion and MALDI-ToF.

\section{SOD Activity Determination}

SOD1 activity in $20 \mu \mathrm{l}$ of 48 -hour MCM concentrated 2- to 4 -fold was determined using the SOD determination kit from Fluka (Sigma-Aldrich). This method is based on the ability of SOD1 to catalyze the dismutation of the anion superoxide, previously produced by xanthine oxidase starting from xanthine and $\mathrm{O}_{2}$, into molecular oxygen and hydrogen peroxide, which in turn can reduce a highly soluble tetrazolium salt (WST-1) to a formazan dye that can be easily revealed through a spectrophotometer. Since the absorbance of formazan dye is proportional to the amount of anion superoxide, SOD activity is quantified as an inhibition activity by measuring the decrease in color development. For quantification, a standard inhibition curve was prepared with a known concentration of exogenous SOD1 (Sigma-Aldrich) from 1.125 to $10 \mathrm{U} / \mathrm{ml}$ and the reaction was followed for at least $20 \mathrm{~min}$.

\section{Immunocytochemistry and Nuclear Staining}

CGNs were fixed for 20 min with $4 \%$ paraformaldehyde in phosphate buffer at $25^{\circ} \mathrm{C}$ and then washed in phosphate-buffered 
saline (PBS). Aspecific sites were blocked with normal goat serum (Sigma-Aldrich) for $1 \mathrm{~h}$ at $25^{\circ} \mathrm{C}$. After several washes, cells were incubated overnight at $4{ }^{\circ} \mathrm{C}$ with both rabbit anti-SOD1 and mouse anti-lysosome-associated membrane protein-1 (LAMP-1; Santa Cruz Biotechnology, Inc., Santa Cruz, Calif, USA) and further incubated with the secondary antibodies for $1 \mathrm{~h}$ and $30 \mathrm{~min}$ at $25^{\circ} \mathrm{C}$ (anti-rabbit fluorescein isothiocyanate for SOD1 and anti-mouse tetramethyl rhodamine isothiocyanate for LAMP-1; Sigma-Aldrich). At the end, nuclei were stained with Hoechst $33258\left(0.1 \mathrm{mg} / \mathrm{ml}\right.$; Sigma) for $5 \mathrm{~min}$ at $25^{\circ} \mathrm{C}$. Stained cultures were photographed with a fluorescence microscope (Eclipse Hoechst staining TE 2000-S microscope; Nikon, Tokyo, Japan) equipped with an AxioCam MRm (Zeiss, Oberkochen, Germany) digital camera.

\section{Western Blot Analysis}

To analyze the level of SOD1 released into the media or expressed by microglial cell cultures after different times of conditioning and/or after treatments with different stimuli, MCM and cells were collected. Five hundred microliters of MCM for each condition were lyophilized using Amicon YM-3 (Millipore) and resuspended in $15 \mu \mathrm{l}$ of loading buffer $2 \times(0.05 \mathrm{M}$ Tris $-\mathrm{HCl} \mathrm{pH}$ $6.8 ; 40 \mathrm{~g} / \mathrm{l}$ sodium dodecyl sulfate; $20 \mathrm{ml} / \mathrm{l}$ glicerol; $2 \mathrm{~g} / \mathrm{l}$ bromophenol blue, and $0.02 \mathrm{M}$ dithiothreitol; all chemicals were from Sigma-Aldrich). In parallel, $1.5 / 10^{6}$ microglial cells from each well were collected directly in $50 \mu \mathrm{l}$ of loading buffer $2 \times$. Fifteen microliters per lane of concentrated MCM samples or of microglial cell samples were loaded onto a $10 \%$ sodium dodecyl sulfate-polyacrylamide gel (SDS-PAGE; Bio-Rad Laboratories). After electrophoresis and transfer to a nitrocellulose membrane (GE Healthcare), the membranes were blocked for $1 \mathrm{~h}$ with a blocking solution made of $5 \%$ nonfat dried milk (Bio-Rad)/0.1\% Tween-20 in phosphate buffer solution (Sigma-Aldrich), $\mathrm{pH} 7.4$, and incubated overnight at $4^{\circ} \mathrm{C}$ with primary antibodies (rabbit polyclonal antiSOD1, 1:1,000; Santa Cruz Biotechnology) in 0.1\% Tween-20/PBS. Then, nitrocellulose membranes were incubated with a secondary antibody, a goat anti-rabbit antibody conjugated to horseradish peroxidase (1:2,000; Santa Cruz Biotechnology), for $90 \mathrm{~min}$ at $24^{\circ} \mathrm{C}$ in $0.1 \%$ Tween-20/PBS. The labeled bands were visualized using the enhanced chemiluminescence method (ECL; Santa Cruz Biotechnology).

\section{Calcium Microfluorometry}

Variations in intracellular free $\mathrm{Ca}^{2+}$ concentration $\left(\left[\mathrm{Ca}^{2+}\right]_{\mathrm{i}}\right)$ were monitored through ratiometric microfluorometry using the fluorescent $\mathrm{Ca}^{2+}$ detector fura-2 AM (Molecular Probes; Invitrogen, Milano, Italy). For microfluorometric experiments the control bath saline was $140 \mathrm{mM} \mathrm{NaCl}, 4 \mathrm{mM} \mathrm{KCl}, 2 \mathrm{mM} \mathrm{MgCl}_{2}, 2 \mathrm{mM}$ $\mathrm{CaCl}_{2}, 10 \mathrm{~mm}$ TES, and $5 \mathrm{~mm}$ glucose, $\mathrm{pH}$ 7.4, with $\mathrm{NaOH}$ and osmolarity adjusted to $\sim 320 \mathrm{mOsm}$ with mannitol. The $\mathrm{Ca}^{2+}$-free extracellular saline was prepared by removing $\mathrm{CaCl}_{2}$ salt and adding $0.5 \mathrm{mM}$ EGTA. When using high $(50 \mathrm{mM}) \mathrm{K}^{+}$external solutions, salts were replaced equimolarly. Stock solution of SOD1 was diluted in control and $\mathrm{Ca}^{2+}$-free media at the final concentrations of $0.75,1.5,3.125,6.25$, and $12.5 \mathrm{U} / \mathrm{ml}$. The 48-hour MCM solution was obtained by dissolving the liophilized powder in $10 \mathrm{ml}$ of the control bath saline with and without calcium. Before measurements, low-density granular cells seeded in coverslips were loaded with $10 \mu \mathrm{M}$ fura-2 AM dissolved in standard bath solution for $45 \mathrm{~min}$ at $25^{\circ} \mathrm{C}$. For microfluorometric analysis cell coverslips were mounted on a perfusion chamber containing $100 \mu \mathrm{l}$ bath saline. Cells were continuously perfused at a rate of $0.5 \mathrm{ml} / \mathrm{min}$ with different salines at room temperature $\left(22-24^{\circ} \mathrm{C}\right)$ as previously described [28]. Measurements of $\left[\mathrm{Ca}^{2+}\right]_{i}$ were performed using an inverted fluorescence microscope (Nikon Eclipse TE2000U; Nikon, Italy) equipped with a long-distance dry objective $(\times 40)$ and appropriate filters. The emission fluorescence of selected astrocytes was passed through a 510-nm narrow-band filter and acquired with a digital charge-coupled device camera (VTi; VisiTech International Ltd., Sunderland, UK). Monochromator settings, chopper frequency, and complete data acquisition were controlled by QuantiCell 2000 (VisiTech). The excitation wavelength was alternated between 340 and $380 \mathrm{~nm}$ with a sampling rate of 0.25 or $0.5 \mathrm{~Hz}$. The fluorescence ratio measured at 340 and 380 $\mathrm{nm}(\mathrm{F} 340 / \mathrm{F} 380)$ was used as an indicator of $\left[\mathrm{Ca}^{2+}\right]_{\mathrm{i}}$ changes. The calibration of the $340 / 380$ ratio in terms of the free $\mathrm{Ca}^{2+}$ concentration was based on the procedure previously described [29].

\section{Statistical Analysis}

All results were subjected to statistical analysis with Student's t test or with one-way ANOVA followed by Bonferroni's post hoc comparisons test in order to evaluate the significance of the differences.

\section{Results}

As previously demonstrated $[22,30]$, exposure of differentiated rat CGNs to the dopaminergic toxin 6-OHDA $(20 \mu \mathrm{M})$ resulted in approximately $50 \%$ cell death after $24 \mathrm{~h}$ (fig. 1a). While a medium conditioned by microglia for $2 \mathrm{~h}$ (2-hour MCM) did not protect neurons from toxicity, media conditioned for 24 and $48 \mathrm{~h}$ (24-hour and 48-hour MCM) showed neuroprotection (fig. 1a, b), thus suggesting that neuroprotective substances released by microglia progressively accumulated in the medium. We previously demonstrated [22] that heat inactivation of the neuroprotective MCM, as well as its pre-treatment with peptidases/proteases, results in a significant decrease in MCM-mediated protection against 6-OHDA neurotoxicity in CGNs, leading to the idea that peptidic factor(s) contribute to neuroprotection. In order to identify the neuroprotective microglia-released proteic factors, we performed a proteomic analysis of 48-hour MCM. This analysis demonstrated the presence of several spots, revealing the accumulation of various peptides in the conditioned medium. Among them, one spot was identified through mass spectroscopy analysis as the $\mathrm{Cu}-\mathrm{Zn}$ superoxide dismutase SOD1 (fig. 2a). Western blot analysis confirmed that SOD1 was actually present and accumulated in 24-hour and 48-hour MCM, while it was much less evident after $2 \mathrm{~h}$ of conditioning (fig. $2 \mathrm{~b}$ ), thus suggesting that SOD1 could contribute to MCM neuroprotection. In order to estimate the amount of this 
Fig. 1. Neuroprotective effect of MCM on 6-OHDA-induced neurotoxicity in CGNs. CGNs were treated for $24 \mathrm{~h}$ with $20 \mu \mathrm{M}$ 6-OHDA in the presence or absence of medium conditioned for 2, 24, and $48 \mathrm{~h}$ by unstimulated microglial cell cultures (100\% of the culture media). Cell viability was determined through MTT assay (a) or visualized via Hoechst staining (b). a Each point is the mean $\pm \mathrm{SE}$ of at least four different experiments run in triplicate. *** $\mathrm{p}<0.001$ compared to the conditions of treatment with 6-OHDA in nonconditioned medium. b Representative Hoechst staining of CGNs cultured for $24 \mathrm{~h}$ in the presence of $20 \mu \mathrm{M}$ 6-OHDA. Note the decrease in cell density caused by exposure to the neurotoxin and the protection of the medium conditioned by microglia for $48 \mathrm{~h}$. Scale bar $=30 \mu \mathrm{M}$.
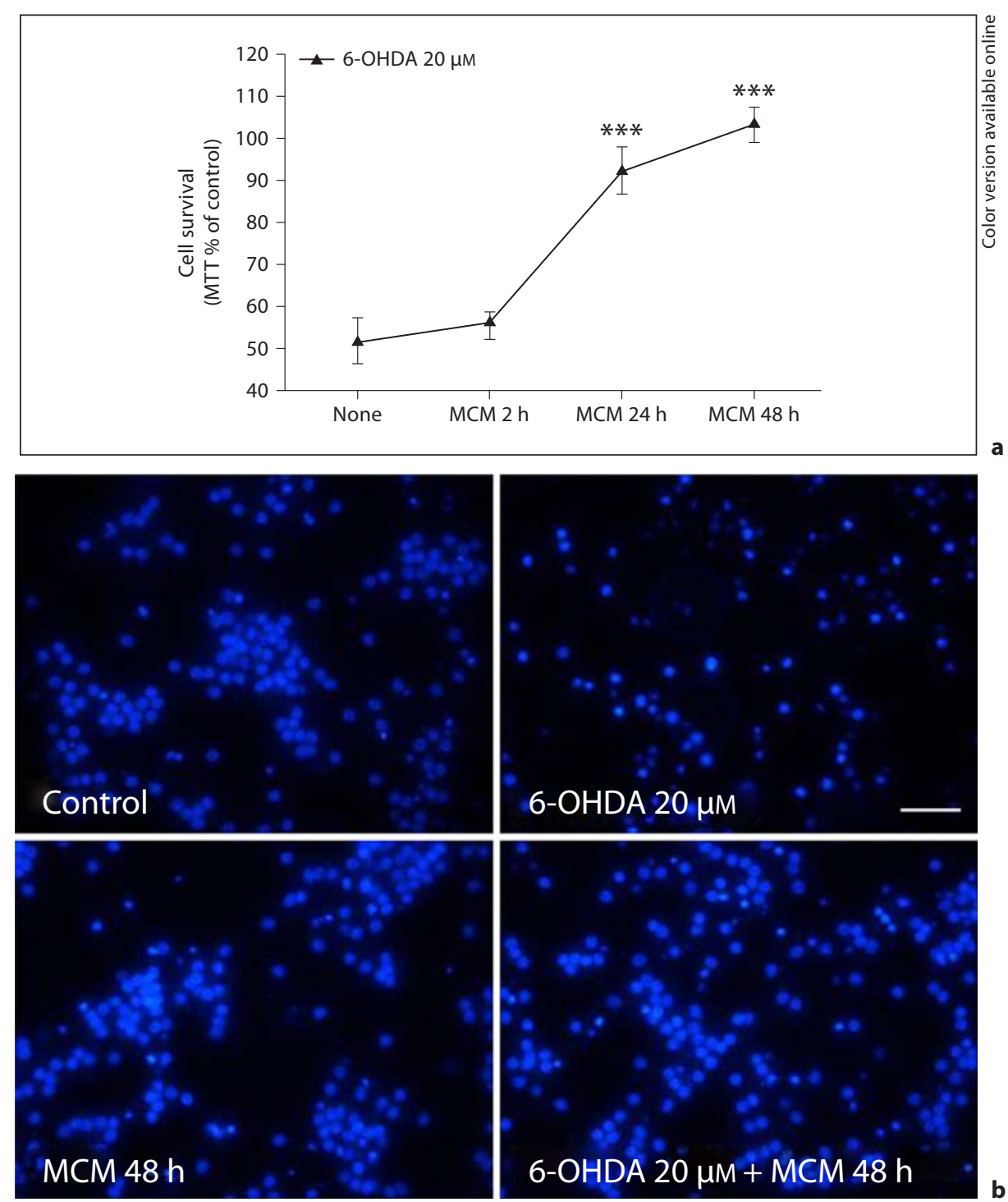

enzyme in the neuroprotective medium (48-hour MCM), we measured its catalytic activity using a commercially available SOD-assay kit (fig. 2c). In parallel, we compared the intensity of Western blot bands derived from a known volume of the 48 -hour MCM (i.e. $500 \mu$ l) with the intensity of bands obtained by loading known amounts of recombinant SOD1 (fig. 2c). Both methods yielded similar values, corresponding to $0.04 / 0.05 \mathrm{U} / \mathrm{ml}$ in the 48 -hour MCM which is around $10 \mathrm{ng} / \mathrm{ml}$ (according to the activity/concentration relationship given by the producer of the recombinant SOD1). As the release and accumulation of SOD1 in the conditioned medium appeared to be constitutive, i.e. related to the normal partially activated in vitro microglial conditions, we tested whether a more activated state could increase SOD1 microglial secretion. Activation of microglia with LPS, IFN- $\gamma$, or both did not increase the SOD1 level in a medium conditioned for $24 \mathrm{~h}$ (fig. 3a) and it did not change the intracellular level of the enzyme, while, as expected, it did induce a strong increase in iNOS expression, thus demonstrating the actual activated state of microglia under these conditions (fig. 3a). SOD1 secretion should be atypical since this protein lacks the secretion signal sequence at its amino terminal polypeptide chain. However, its extracellular release has been well documented in several cell types through a mechanism involving a vesicle-related and, in some cases, ATP-dependent pathway [30-36]. Since ATP has been shown to stimulate the 
Fig. 2. Identification of SOD1 release and accumulation in the MGM. a Microglial cell cultures were maintained for $48 \mathrm{~h}$ in medium (from $60 \times 10^{6}$ microglial cells) were purified from BSA and $400 \mu \mathrm{g}$ of total proteins were separated according to their isoelectric point followed by standard SDS-PAGE, as described in Materials and Methods. A representative Coomassie Blue-stained 2-D gel is illustrated and the arrow indicates the position of the spot identified as SOD1. b Representative Western blot analysis of SOD1 protein expression in different media conditioned by microglia for 2, 24, and $48 \mathrm{~h}$. c Determination of SOD1 units in 48-hour MCM through two different methods: comparative analysis of SOD1 protein expression (Western blot) in 48-hour MCM, compared to different known units of SOD1 from human erythrocytes, and determination of SOD activity using a specific kit. serum-free medium. Then, $60 \mathrm{ml}$ of the

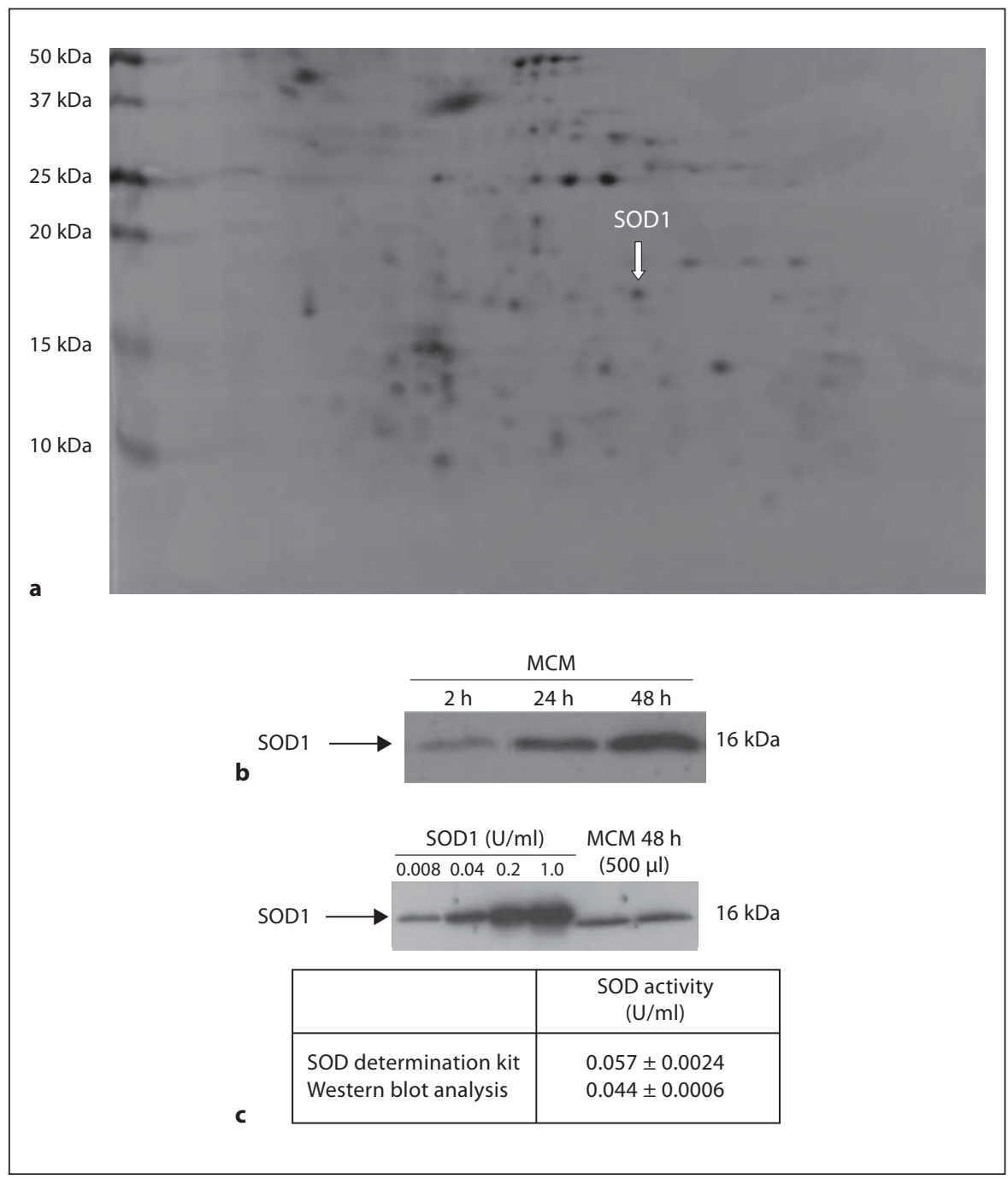

extracellular release of the lysosomal compartment content from microglia $[37,38]$, we investigated the effect of this purine on microglial SOD1 secretion. As shown in figure $3 \mathrm{~b}, 1 \mathrm{~h}$ of stimulation with $500 \mu \mathrm{M}$ ATP increased the level of SOD1 in culture medium, thus suggesting that SOD1 could be released by microglial cells through a lysosomal secretory pathway. To further support this hypothesis, we studied SOD1 co-localization with LAMP-1, a vesicular marker of the lysosomal secretory pathway, using an immunocytochemical approach [39]. Therefore, we performed double immunofluorescent staining with an antibody against SOD1 and one against LAMP-1. This analysis demonstrated that the finely granular and partially overlapping cytoplasmic distribution of the two proteins in unstimulated microglia (fig. 3c, upper panel) shifted towards a clear co-localiza- tion in secretory granules after $1 \mathrm{~h}$ of ATP stimulation (fig. 3c, lower panel).

In order to demonstrate a relationship between SOD1 accumulated in MCM and neuroprotection, we added different amounts of exogenous SOD1 to a nonconditioned medium, thus testing it for neuroprotection in 6-OHDA-challenged CGNs. Exogenously added SOD1 was significantly neuroprotective under these conditions, although at concentrations $\sim 40$ times higher than those estimated in MCM (fig. 4a). Contradictory previously published results $[40,41]$ suggested that SOD1 could inhibit the spontaneous process of 6-OHDA autooxidation, leading to generation of superoxide radicals and quinones putatively responsible for neurotoxicity. In order to ensure that, in our conditions, SOD1 neuroprotection was a true biological effect and not simply the 
Fig. 3. Constitutive release of SOD1 by microglial cells is not modulated by pro-inflammatory agents but is increased by ATP. a SOD1 protein expression was analyzed using Western blot in different conditioned media and in cell lysates of microglia cell cultures treated or co-treated for $24 \mathrm{~h}$ with different concentrations of LPS and IFN- $\gamma$. The increase in the intracellular expression of iNOS was also analyzed to confirm microglial activation. b The microglial release of SOD1 was detected via Western blot in the medium of microglial cell cultures stimulated for $1 \mathrm{~h}$ with $500 \mu$ M ATP. c Immunocytochemical analysis of SOD1 and LAMP-1 in microglial cell cultures in basal conditions or after stimulation with $500 \mu \mathrm{M}$ ATP for $1 \mathrm{~h}$. Note how treatment induces a much more evident co-localization of SOD1 with LAMP-1 in vesicles of the lysosomal secretory pathway. Scale bar $=10 \mu \mathrm{M}$. C = Control.

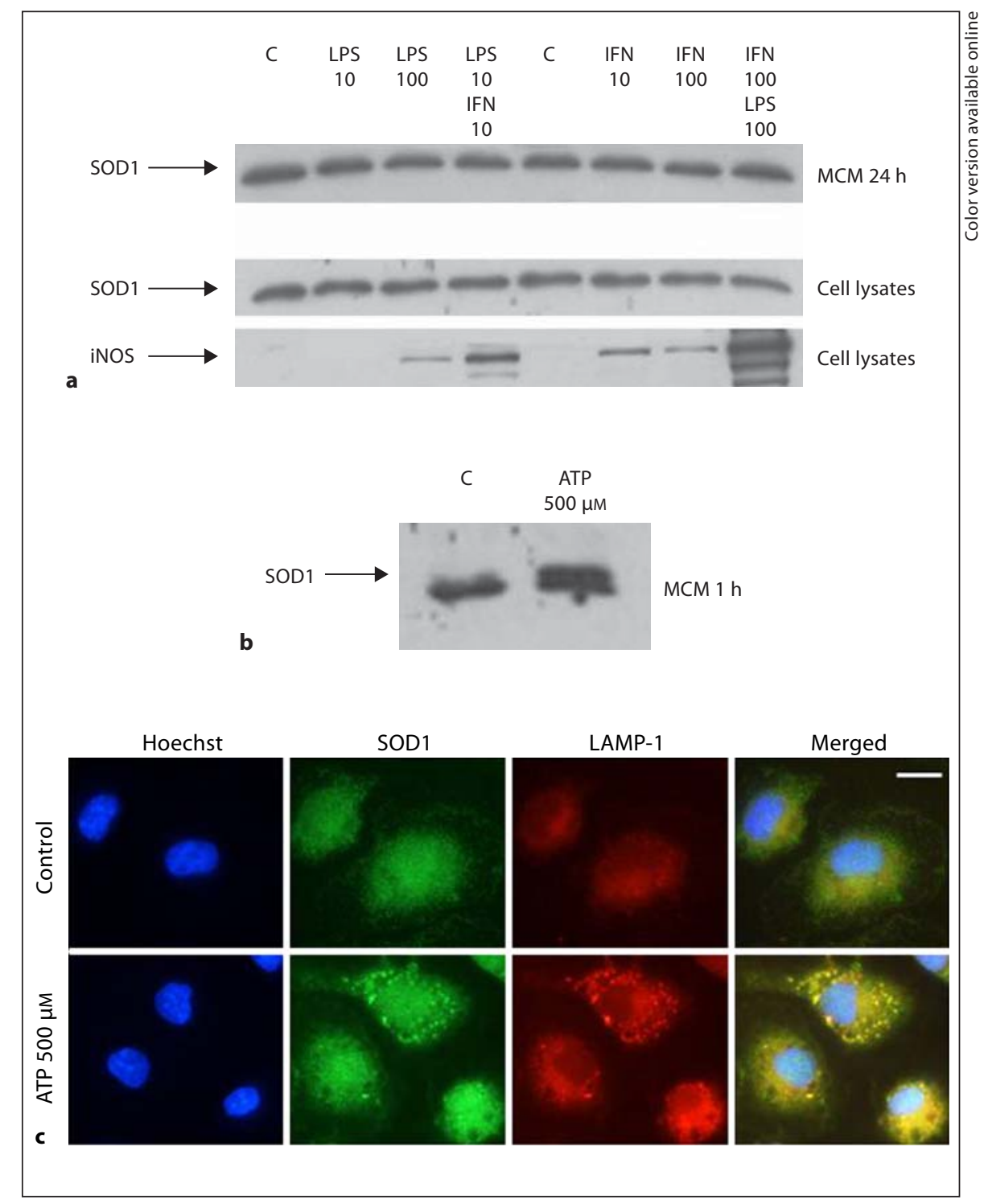

result of a toxin concentration decrease in the medium due to a purely chemical effect, we performed a specific control experiment. Nonconditioned medium containing $20 \mu \mathrm{M}$ 6-OHDA was pre-incubated for 2 or $6 \mathrm{~h}$ with a strongly neuroprotective concentration of SOD1 (12.5 $\mathrm{U} / \mathrm{ml}$ ), and then this medium was passed through a filter with a molecular cutting of $10 \mathrm{kDa}$ in order to trap SOD1, but not 6-OHDA, thus leaving the toxin in the medium. The resulting medium maintained the same toxic potency of a medium to which $20 \mu \mathrm{M} 6$-OHDA has been freshly added (fig. 4b). These data showed that preincubation with SOD1 did not result in dampened neurotoxicity of 6-OHDA attributable to an SOD1-depen- dent chemical modification, thus demonstrating that SOD1-mediated neuroprotection was not due to a nonspecific decrease in 6-OHDA neurotoxicity but was the result of an unambiguous neuroprotective effect of this protein.

In an attempt to demonstrate the specificity of the SOD1 neuroprotective effect in the MCM, we tried to deplete the medium by knocking down the SOD1 expression in microglial cells through an siRNA approach. With Western blot analysis we observed a partial decrease, but not complete abrogation, of SOD1 in the medium conditioned for $48 \mathrm{~h}$ by the siRNA-transfected microglial cells, as MCM maintained its neuroprotective 


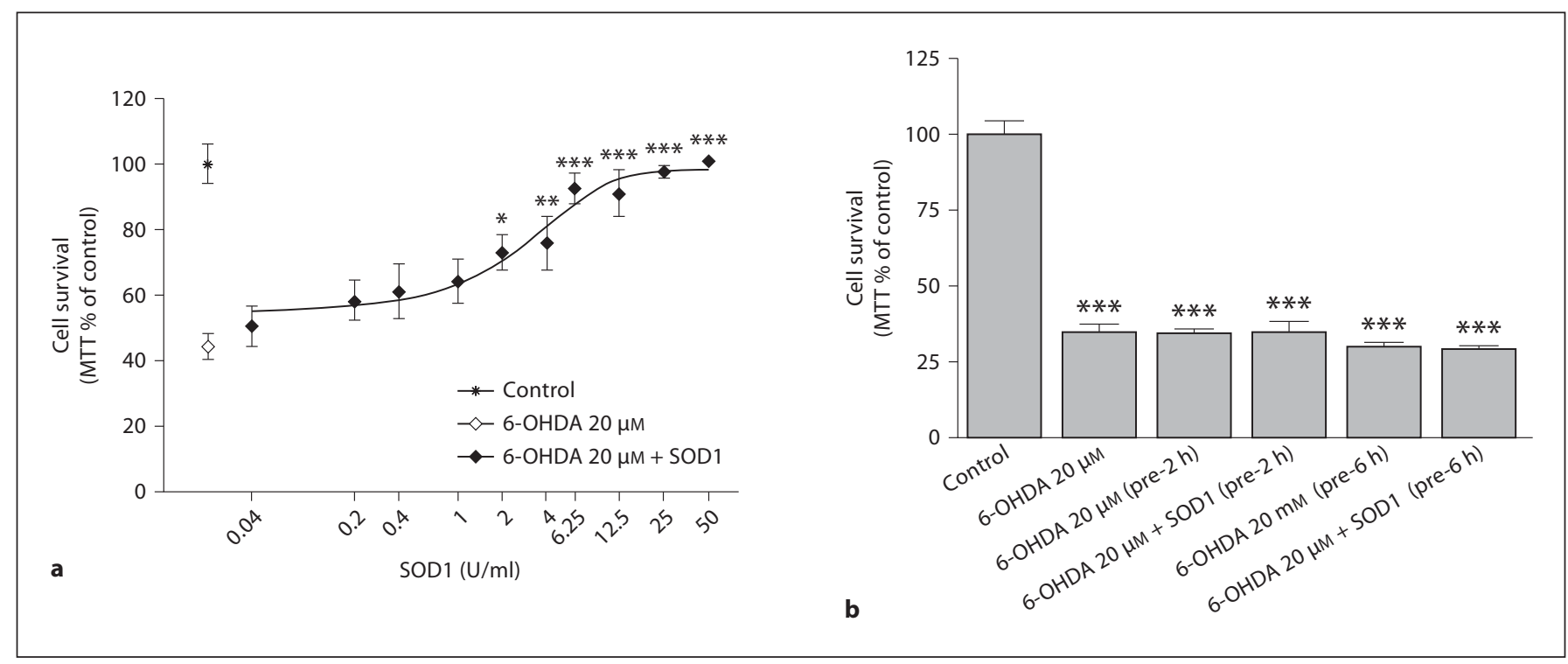

Fig. 4. Effect of exogenous SOD1 on neurotoxicity induced in CGNs by 6-OHDA. a Cell survival (MTT assay) of CGN cultures treated for $24 \mathrm{~h}$ with $20 \mu \mathrm{M}$ 6-OHDA in the presence or absence of different amounts of exogenous SOD1 (0.04-50 U/ml). Each point is the mean $\pm \mathrm{SE}$ of eight different experiments run in triplicate. ${ }^{*} \mathrm{p}<0.05 ;{ }^{* *} \mathrm{p}<0.01 ;{ }^{* *} \mathrm{p}<0.001$ compared to 6-OHDA treatment. b Cell survival (MTT assay) of CGN cultures treated for $24 \mathrm{~h}$ with $20 \mu \mathrm{M} 6-\mathrm{OHDA}$ freshly prepared or $20 \mu \mathrm{M} 6-\mathrm{OHDA}$ pre-incubated for $2 \mathrm{~h}$ at $37^{\circ} \mathrm{C}$ with or without SOD1 $(12.5 \mathrm{U} / \mathrm{ml})$. Bars are the means $\pm \mathrm{SE}$ of four different experiments run in triplicate. ${ }^{* *} \mathrm{p}<0.001$ compared to control conditions. Bonferroni's test after ANOVA. activity (online suppl. fig. 1; for all online suppl. material, see www.karger.com/doi/10.1159/000337115). Considering that silencing its expression was not an adequate method to block SOD1 in our experimental model, we decided to use a pharmacologic approach to interfere both with the catalytic activity of SOD1 and with the ability of this protein to regulate target cells through receptor interactions. To this aim, we used two SOD1 inhibitors, ammonium tetrathiomolibdate and disulfiram [42-44], and we showed that both of them were able to fully reverse the effect of neuroprotective concentrations of exogenous SOD1 (fig. 5a, b). Moreover, these SOD1 inhibitors substantially decreased the neuroprotective potency of 48-hour MCM against 6-OHDA neurotoxicity (fig. 5c, d), thus confirming the neuroprotective role of SOD1 in the MCM.

In view of previous evidence that released SOD1 could regulate cellular calcium levels in a paracrine way through receptor-mediated interactions in neuroblastoma cells [45-47], we sought to analyze the involvement of a similar mechanism in the neuroprotective action of the protein and of the conditioned medium containing it. To this end, a microfluorometric analysis of intracellular calcium dynamics was performed in $2 \mathrm{mM}\left[\mathrm{Ca}^{2+}\right]_{0}$ by measur- ing changes in the fluorescence emission ratio of fura2-loaded CGNs. Extracellular challenge with SOD1 (6.25 $\mathrm{U} / \mathrm{ml}$ ) promoted a significant rise in $\left[\mathrm{Ca}^{2+}\right]_{\mathrm{i}}$ (fig. 6). Notably, $90 \%$ of all of the granular cells tested responded to SOD1, and the viability of responding and nonresponding cells was checked in every experiment by the application of high $\mathrm{K}^{+}(50 \mathrm{mM})$ external solution (not shown). The $\left[\mathrm{Ca}^{2+}\right]_{\mathrm{i}}$ responses were variable both in amplitudes and dynamics depending on the presence of the extracellular calcium. The most representative behavior in calcium dynamics in response to SOD1 was a significant increase in $\left[\mathrm{Ca}^{2+}\right]_{\mathrm{i}}$ signals occurring with a time lag of $\sim 2$ min (fig. 6a). The $\left[\mathrm{Ca}^{2+}\right]_{\mathrm{i}}$ responses were always dependent on $\left[\mathrm{Ca}^{2+}\right]_{0}$ presence because omission of extracellular $\mathrm{Ca}^{2+}$ caused a rapid reduction of $\left[\mathrm{Ca}^{2+}\right]_{i}$ signals as a result of administration of SOD1 (fig. 6a). This result was corroborated by the fact that when perfusion of neurons started in SOD1-containing, $\mathrm{Ca}^{2+}$-free medium there was no response until $\mathrm{Ca}^{2+}$ was added to the medium (fig. 6b). Responses similar to those described for the addition of exogenous SOD1 were elicited by SOD1containing medium conditioned for $48 \mathrm{~h}$ by microglia (fig. 6c, d). Conversion of fluorimetric data into direct evaluation of intracellular calcium levels and statistical 


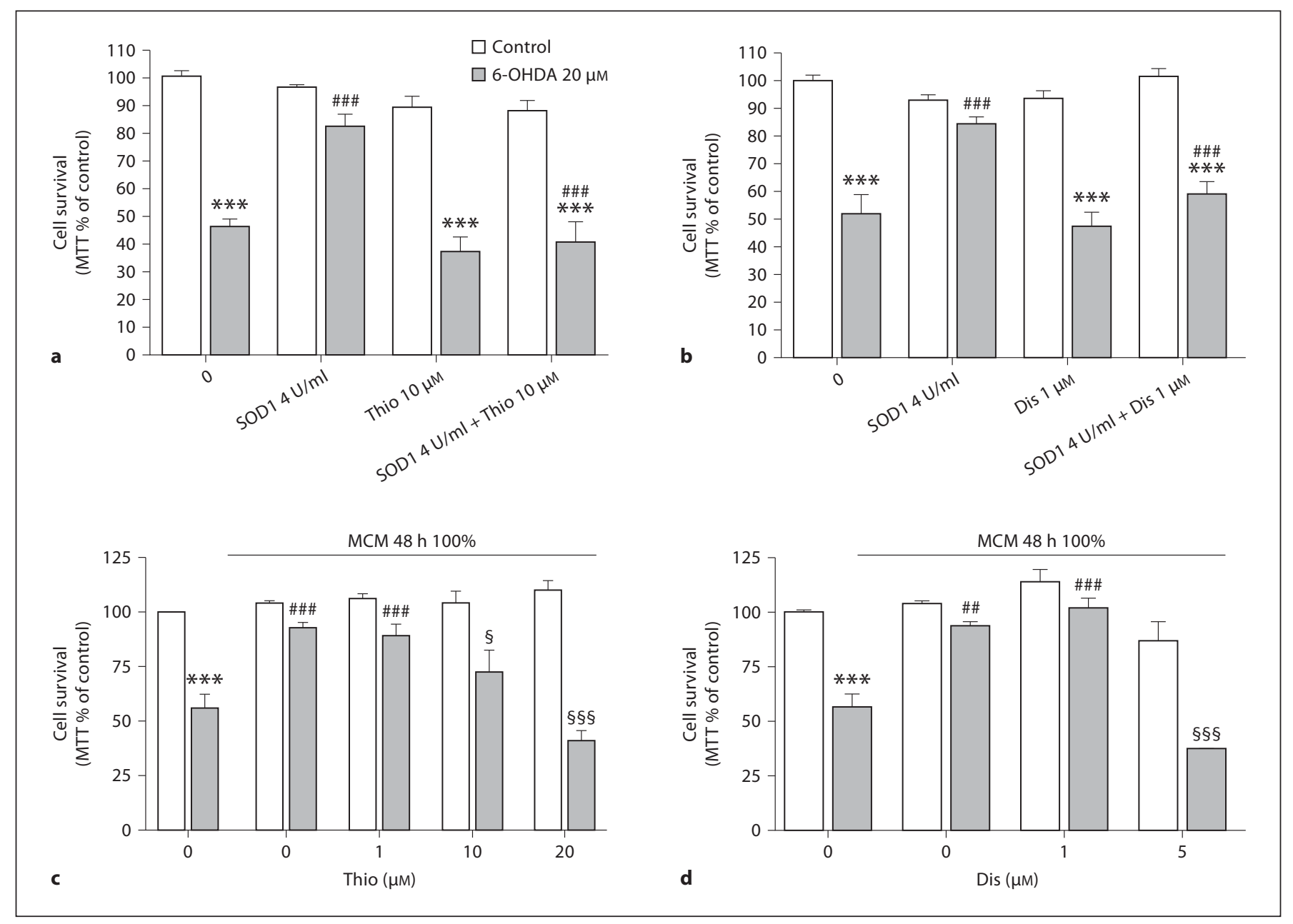

Fig. 5. Two inhibitors of superoxide dismutase, ammonium tetrathio-molybdate (Thio) and disulfiram (Dis), block the neuroprotective effect of exogenous SOD1 and MCM. Thio $10 \mu \mathrm{M}$ (a) or Dis $1 \mu \mathrm{M}$ (b) was added to CGN cultures treated for $24 \mathrm{~h}$ with $20 \mu \mathrm{M}$ 6-OHDA in the presence or absence of exogenous SOD1 (4 U/ml). Cell survival was analyzed via MTT assay. Bars are the means \pm SE of four different experiments run in triplicate. ${ }^{* *} \mathrm{p}<0.001$ compared to its own control condition; ${ }^{\# \#} \mathrm{p}<0.01$ compared to the 6-OHDA condition (with neither SOD1 nor the SOD inhibitor); ${ }^{\$ \$} \mathrm{p}<0.001$ compared to the parallel SOD1 condition (with 6-OHDA and SOD1 at the same concentration but without the
SOD inhibitor). Thio $(10$ or $20 \mu \mathrm{M})$ (c) or Dis $(1$ or $5 \mu \mathrm{M})(\mathbf{d})$ was added to the cultures of CGNs treated for $24 \mathrm{~h}$ with $20 \mu \mathrm{M}$ 6-OHDA in presence or absence of medium conditioned for $48 \mathrm{~h}$ by unstimulated microglial cell cultures $(100 \%$ of the culture media). Cell survival was analyzed through MTT assay. Bars are the means \pm SE of four different experiments run in triplicate. ${ }^{* * *} \mathrm{p}<0.001$ compared to control conditions; ${ }^{\# \#} \mathrm{p}<0.001$, $\# \#$ p $<0.001$ compared to 6-OHDA conditions (with neither 48hour MCM nor the SOD inhibitor); ${ }^{\S} \mathrm{p}<0.05,{ }^{\circledR \S \S} \mathrm{p}<0.001 \mathrm{com}-$ pared to the condition with 6-OHDA and 48-hour MCM (without the SOD inhibitor). Bonferroni's test after ANOVA. analyses confirmed that SOD1-induced calcium signals were significantly higher than at baseline and dependent upon $\left[\mathrm{Ca}^{2+}\right]_{\mathrm{o}}$ (fig. 6e). Altogether, these data suggest that perfusion with SOD1 promotes complex $\left[\mathrm{Ca}^{2+}\right]_{\mathrm{i}}$ signals that are dependent on the presence of $\left[\mathrm{Ca}^{2+}\right]_{0}$. Interestingly, administration of SOD1 at different concentrations, from 0.75 to $12.5 \mathrm{U} / \mathrm{ml}$, was able to induce a dosedependent increase in $\left[\mathrm{Ca}^{2+}\right]_{\mathrm{i}}$ (fig. 7a). In order to verify whether the effect of SOD1 on calcium dynamics depended on its catalytic activity, we performed a control experiment in which an SOD1 mimetic substance, MnTMPyP, possessing similar catalytic activity failed to affect the calcium dynamics (data not shown), similarly to what previously shown in neuroblastoma cells [45]. On the basis of these results, we supposed that if the calcium flux was important for neuroprotection, interfering with it 

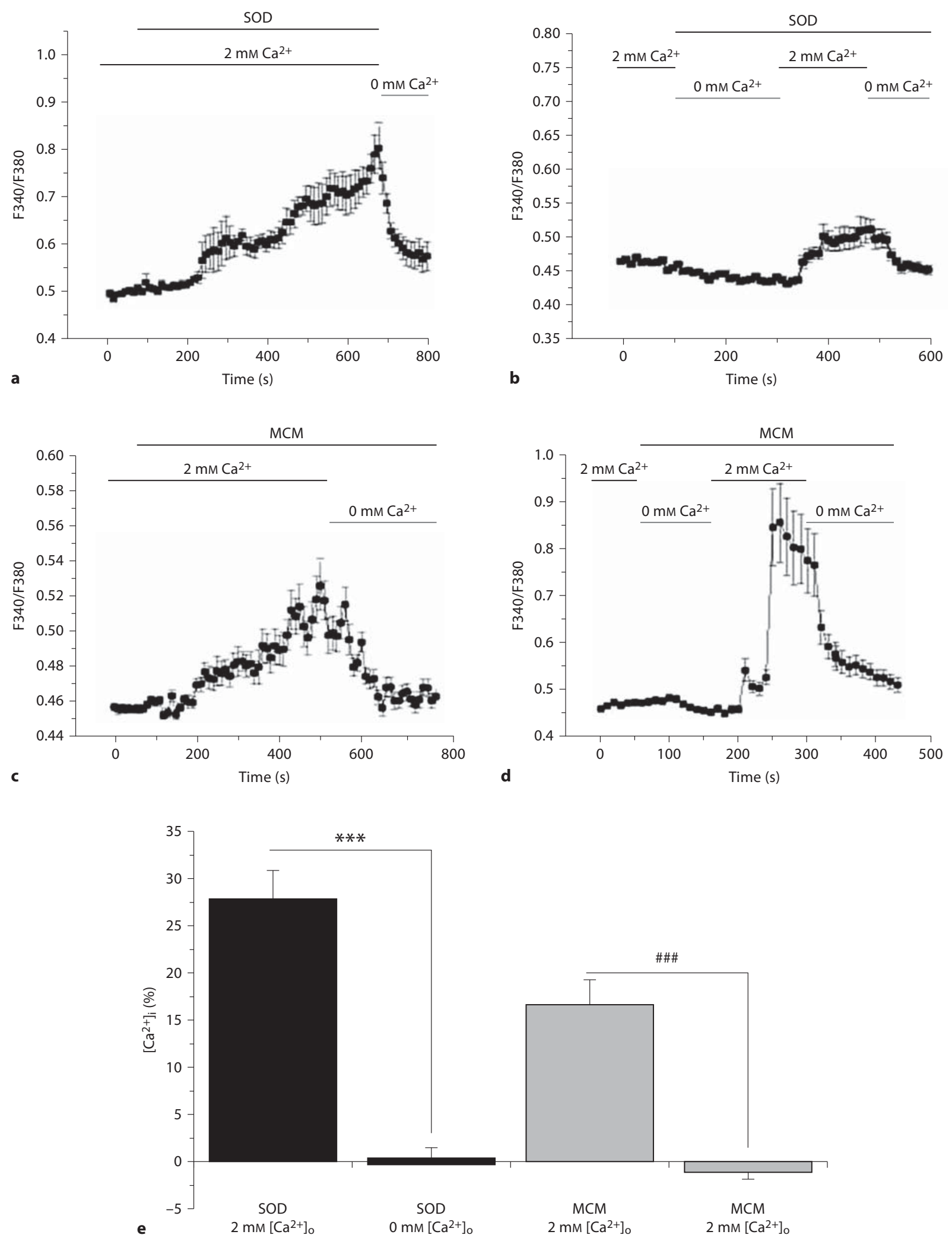

6

Neuroprotection by Microglia-Released

Neurosignals 2013;21:112-128 
could abrogate the neuroprotection provided by SOD1 itself, either exogenously added or endogenously present in the conditioned medium. This was actually the case since the extracellular $\mathrm{Ca}^{2+}$ chelator EDTA, which has no effect on the $\mathrm{Cu}-\mathrm{Zn}$ site of SOD1 [48], significantly reverted neuroprotection mediated by exogenous SOD1 and by 48-hour MCM (fig. 7b).

To investigate the specificity of SOD1 protection against different forms of neurotoxicity, we added the recombinant enzyme at high concentrations to CGNs exposed to two well-known and widely used models of neurotoxicity, i.e. a shift from high to low potassium medium or chronic exposure to glutamate. While, in agreement with our previous results [16, 19], 48-hour MCM significantly protected CGNs in both conditions, addition of exogenous SOD1 to a nonconditioned medium had no significant neuroprotective effects (fig. 8a, b). These results confirmed that the neuroprotective effect of SOD1 was specific towards 6-OHDA-induced neurodegeneration and suggested that microglia-mediated neuroprotection could be exerted by multiple released factors with diverse effects on different types of neurodegeneration, further demonstrating the complexity of microglia-mediated neuroprotection.

\section{Discussion}

In the present work, we started to characterize neuroprotective molecules produced and released by microglia by means of their identification through proteomic analysis of media conditioned by rat primary microglial cultures. Using this approach, we present here novel evi-

Fig. 6. SOD1 and MCM promote $\left[\mathrm{Ca}^{2+}\right]_{\mathrm{i}}$ elevation in cultured CGNs. Representive variations in $\left[\mathrm{Ca}^{2+}\right]_{\mathrm{i}}$ measured in fura-2loaded cultured CGNs stimulated with $6.25 \mathrm{U} / \mathrm{ml}$ SOD1 in the presence (a) and absence of $2 \mathrm{mM}\left[\mathrm{Ca}^{2+}\right]_{\mathrm{o}}$ (b). Representative $\left[\mathrm{Ca}^{2+}\right]_{\mathrm{i}}$ traces measured upon MCM challenge in the presence $(\mathbf{c})$ and absence of $2 \mathrm{mM}\left[\mathrm{Ca}^{2+}\right]_{\mathrm{o}}(\mathbf{d})$. The traces are representative of 10-15 cells of each experimental group studied in at least three different experimental sessions. e Histogram of the mean increase in maximal $\left[\mathrm{Ca}^{2+}\right]_{\mathrm{i}}$ rise with respect to the basal level upon exposure to $6.25 \mathrm{U} / \mathrm{ml} \mathrm{SOD1}$ (d) and MCM with and without $\left[\mathrm{Ca}^{2+}\right]_{\mathrm{o}}$. The results are reported as intracellular calcium increases (\% peak/basal). Data are expressed as the means \pm SE of several cells in the various conditions. Triple marks indicate the statistical analysis performed with Student's t test. ${ }^{* *} \mathrm{p}<0.001 \mathrm{com}-$ pared the effect of SOD1 on $\left[\mathrm{Ca}^{2+}\right]_{\mathrm{i}}$ to $\left[\mathrm{Ca}^{2+}\right]_{\mathrm{o}}$ conditions; ${ }^{\# \# \#} \mathrm{p}<$ 0.001 compared the effect of MCM on $\left[\mathrm{Ca}^{2+}\right]_{i}$ to $\left[\mathrm{Ca}^{2+}\right]_{0}$ conditions. dence that a neuroprotective protein accumulated in the MCM is the enzyme SOD1, which we show protected CGNs from death caused by the neurotoxin 6-OHDA. We confirmed the neuroprotective action of SOD1 by adding the exogenous protein to a nonconditioned medium and by inhibiting it through SOD1 antagonists. SOD1 neuroprotective action was mediated by increased cell calcium from an external source, and full neuroprotection depended on the maintenance of extracellular free calcium levels.

The identification of microglia-released molecules through the proteomic dissection of 'microglia secretoma' in culture conditions, which are close to the physiologic situation, is essential to better understanding the neuroprotective properties of these cells and may lead to discovery of new neuroprotective microglia-secreted molecules [49-52]. In recent years, several studies have focused on strategies of immunomodulation to specifically increase neuroprotective phenotypes of microglial cells [53-56], mainly through the release of neuroprotective molecules, whose identification and characterization could be very important for developing novel therapies $[8,57]$. Previous proteomic studies $[49,50]$ have detected SOD1 among the proteins released by microglia, even following activation. While superoxide dismutase is usually released by cells in its SOD3 isoform [58, 59], also SOD1 is released by several cell lines [31-34]. Moreover, high concentrations of SOD1 may protect neurons from some toxic insults [60-66]. Here we show that SOD1 is produced and released by microglia and is a neuroprotective factor against 6-OHDA neurotoxicity in CGNs.

We have recently succeeded in identifying TGF- $\beta 2$, a known regulator of neuronal survival [67], as an active neuroprotective molecule released by microglia, and other groups have found additional factors [20, 23, 68, 69].

From our data, SOD1 appears to be constitutively released by cultured microglia, as it accumulates in the medium in the absence of experimentally induced activation. Stimulation for $24 \mathrm{~h}$ with known pro-inflammatory activators of microglia did not affect SOD1 production and release. This lack of effect on SOD1 agrees with previous data showing that pro-inflammatory cytokines stimulate expression of SOD2 and SOD3, but not SOD1, in microglia [70, 71]. Interestingly, we demonstrate here that ATP increases the constitutive release of SOD1 in the medium, in agreement with a general modulatory response of microglia to this nucleotide [72, 73]. Release of SOD1 has been demonstrated to be ATP dependent through a microvesicle pathway in neuronal cell lines [34], and secretion of several proteins occurs 


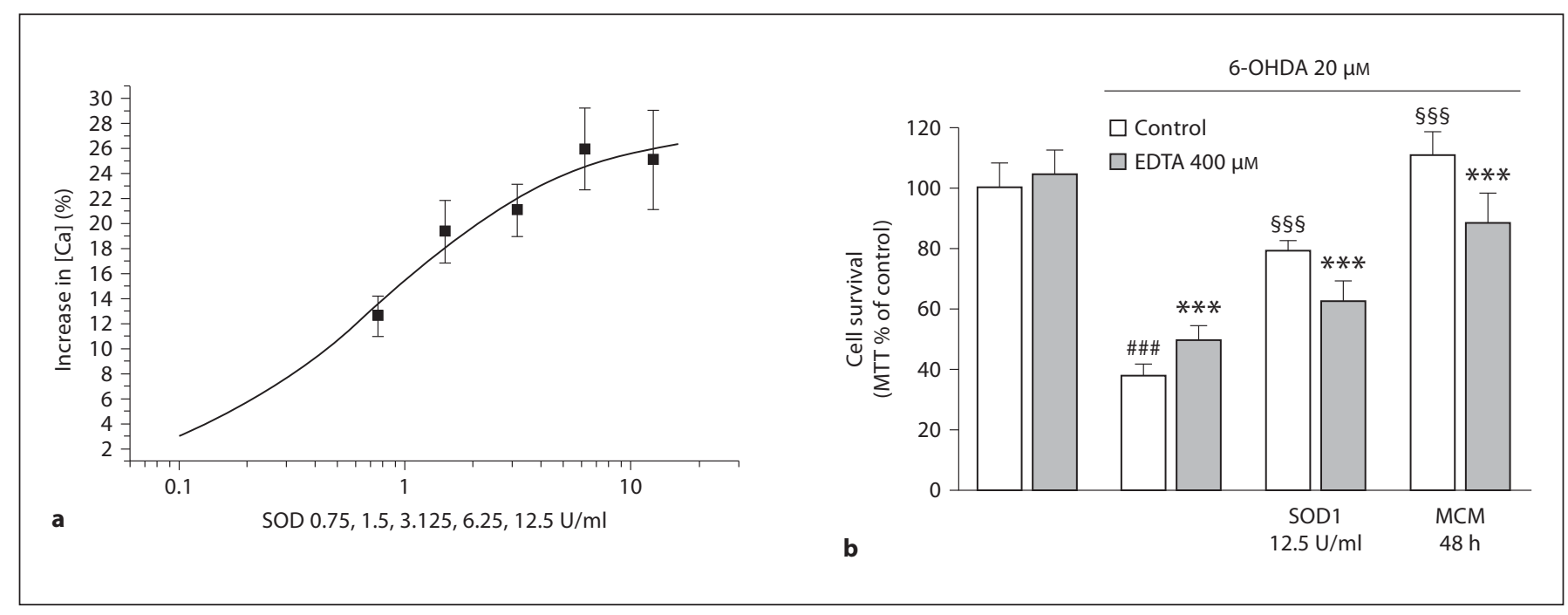

Fig. 7. SOD1 promotes $\left[\mathrm{Ca}^{2+}\right]_{\mathrm{i}}$ elevation in cultured $\mathrm{CGN}$ s and the extracellular $\mathrm{Ca}^{2+}$ chelator EDTA decreases the neuroprotective effect of both MCM and SOD1 on 6-OHDA neurotoxicity. a Dose-dependent effect curve of SOD1 on $\left[\mathrm{Ca}^{2+}\right]_{\mathrm{i}}$ increase at different concentrations $(0.75,1.5,3.125,6.25$, and $12.5 \mathrm{U} / \mathrm{ml})$. The results are reported as intracellular calcium increases (\% peak/ basal) and are representative of 25-30 cells of each experimental group studied in at least three different experimental sessions.
The plot was fitted to the equation $y=\max \cdot x /(x+k) . \mathbf{b}$ MTT assay on CGN cultures treated for $24 \mathrm{~h}$ with $20 \mu \mathrm{M}$ 6-OHDA in the presence or absence of exogenous SOD1 $12.5 \mathrm{U} / \mathrm{ml}, 48 \mathrm{~h}$ $\mathrm{MCM}$, and $400 \mu \mathrm{M}$ EDTA. Bars are the means \pm SE of $6-8$ experiments; \#\# $\mathrm{p}<0.001$ compared to the control without 6 OHDA; ${ }^{\circledR s \$} \mathrm{p}<0.001$ compared to the control with 6-OHDA; *** $\mathrm{p}<0.001$ compared to its own control with 6-OHDA.

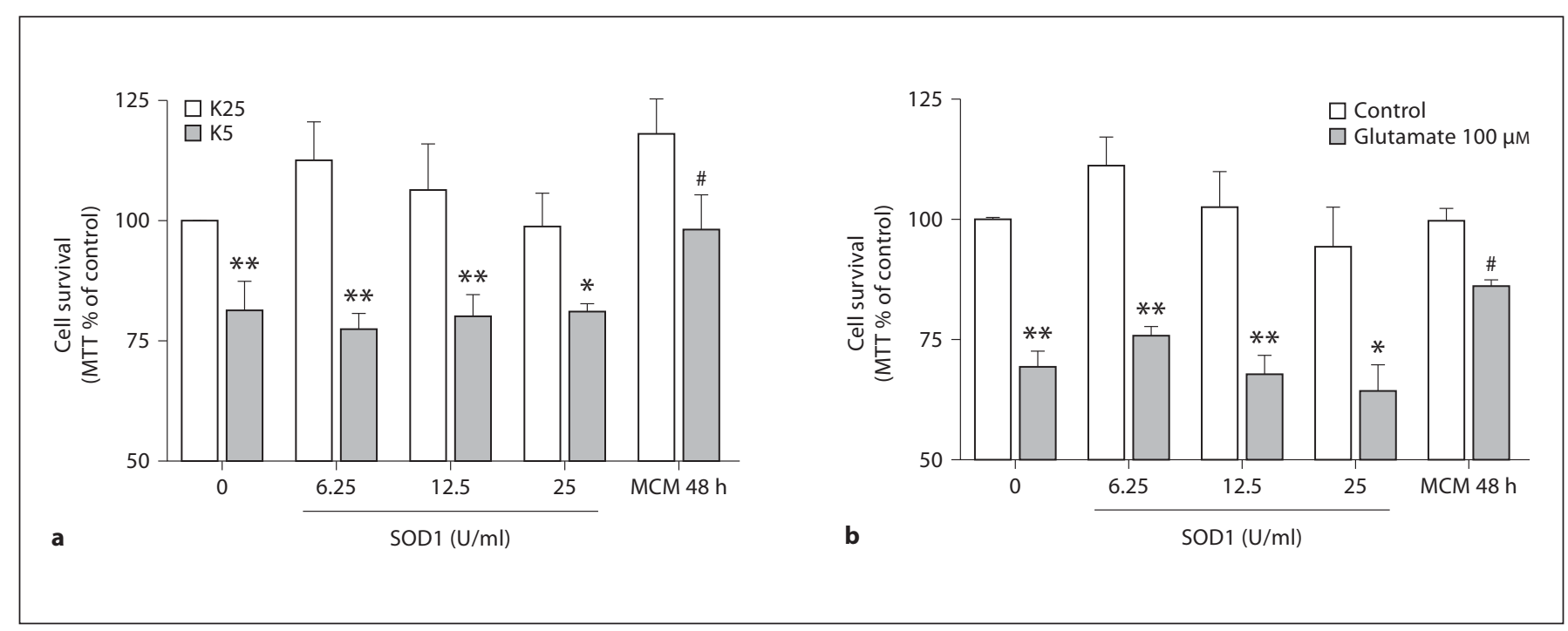

Fig. 8. Effect of exogenous SOD1 on different models of neurotoxicity induced in CGCs by a shift to low potassium and glutamate excitotoxicity. a Cell survival (MTT assay) of CGN cultures shifted to low potassium for $24 \mathrm{~h}$ in the presence or absence of different amounts of exogenous SOD1 $(6.25,12.5$, and $25 \mathrm{U} / \mathrm{ml})$ or of medium conditioned for $48 \mathrm{~h}$ by unstimulated microglial cell cultures (100\% of the culture media). Bars are the means \pm SE of four different experiments run in triplicate. ${ }^{*} \mathrm{p}<0.05 ;{ }^{* *} \mathrm{p}<0.01 \mathrm{com}$ pared to its own control condition; ${ }^{\#} \mathrm{p}<0.05$ compared to low potassium conditions (without SOD1). b Cell survival (MTT assay) of CGNs cultures treated for $24 \mathrm{~h}$ with $100 \mu \mathrm{M}$ glutamate in the presence or absence of different amounts of exogenous SOD1 $(6.25,12.5$, and $25 \mathrm{U} / \mathrm{ml})$ and of medium conditioned for 48 hy unstimulated microglial cell cultures (100\% of the culture media). Bars are the means $\pm \mathrm{SE}$ of four different experiments run in triplicate. ${ }^{*} \mathrm{p}<0.05 ;{ }^{* *} \mathrm{p}<0.01$ compared to its own control condition; ${ }^{*} \mathrm{p}<0.05$ compared to glutamate conditions (without SOD1). Bonferroni's test after ANOVA. 
through a lysosomal secretory pathway in microglial cells $[37,38]$. The evidence here presented that microglial ATP exposure results in a rapid increase in SOD1 localization in secretory vesicles and in the parallel increase in SOD1 released in the medium strongly argues in favor of this noncanonical secretion of the enzyme by microglia cells.

By adding exogenous SOD1 to a nonconditioned medium, even at concentrations remarkably higher than those present in the conditioned medium, we have reproduced the neuroprotective effect on 6-OHDA insult to CGNs. This raises the obvious question of the actual contribution of the low SOD1 concentration present in the conditioned medium to its neuroprotective action. Explanation of this apparent contradiction likely resides in the fact that the low SOD1 concentration present in the conditioned medium could cooperate with other neuroprotective factors, such as the ones mentioned in the introduction (TGF- $\beta 2$, apolipoprotein E, and plasminogen), to protect neurons $[21,22,27]$. Consequently, it is not surprising that when SOD1 is added as the only neuroprotective molecule to a nonconditioned medium higher concentrations are required. In addition, the SOD1 increase in the medium conditioned for $24 \mathrm{~h}$ by primary microglia transfected with plasmids expressing human wild-type SOD1 (see online suppl. fig. 2) does not show any improvement in neuroprotection compared to the 24-hour standard conditioned medium (fig. 1a), thus confirming that the amount of protein normally released by microglia is enough to grant protection. Conceivably, once proteomic studies have definitely disclosed the pattern of neuroprotective molecules released by microglia in the medium, it could be possible to design specific mixtures of molecules granting neuroprotection at individually low concentrations through an additive/synergic effect. In this respect, it is relevant to consider that exogenous SOD1, even at very high concentrations, is not able to protect CGNs from neurotoxicity caused by other neurotoxic agents besides 6-OHDA. Therefore, the identification of other microglia-released factors involved in neuroprotection will likely contribute to explaining why other types of neurotoxicity (a shift of CGNs to nondepolarizing conditions or excitotoxicity) are significantly reverted by MCM, but not by exogenous SOD1. Differences in SOD1 neuroprotection against different toxic stimuli are in line with previous works that have or have not found neuroprotective effects of SOD1 in nonconditioned media, sometimes using very high amounts of exogenously added protein [60-66]. To further complicate this situ- ation, it has to be considered that SOD1 may act on target cells both through its catalytic activity and through receptor interaction $[46,47]$. In the present study, we started to characterize the mechanism of neuroprotection mediated through SOD1. We found that SOD1-mediated neuroprotection depends on increased cellular calcium from an external source. Furthermore, we obtained preliminary evidence that this mechanism does not depend on the protein catalytic activity but it could be attributed to a receptor-mediated mechanism, as previously observed in neuroblastoma cells [45]. This mechanism, together with the fact that there is an SOD1 concentration-dependent increase in $\mathrm{Ca}^{2+}$ entry into CGNs and a concomitant decrease in neuroprotection in the presence of the $\mathrm{Ca}^{2+}$ chelator EDTA in the medi$\mathrm{um}$, strongly suggests that SOD1 neuroprotection is related to a $\mathrm{Ca}^{2+}$ increase from an extracellular source. This knowledge could pave the way for future steps aimed to fully characterize the cellular neuroprotective pathway elicited by SOD1. Moreover, identification of the intracellular $\mathrm{Ca}^{2+}$ increase as a mechanism involved in SOD1-mediated neuroprotection could also explain the lack of an SOD1 neuroprotective effect against other types of neurotoxic stimuli for CGNs, i.e. the shift to nondepolarizing conditions and the excitotoxicity of glutamate, as shown here. In fact, $\mathrm{Ca}^{2+}$ entry from the extracellular compartment is limited if the neuronal membrane is not depolarized, as occurs in the first type of neuronal death mentioned above, since in this condition both voltage-sensitive $\mathrm{Ca}^{2+}$ channels and NMDA receptors, which are the main ways of entrance for $\mathrm{Ca}^{2+}$ in these cells, are inactive [74]. Instead, it could be supposed that SOD1 is not neuroprotective against glutamate excitotoxicity, as this type of neurodegeneration is largely attributable to an excessive increase in the intracellular calcium levels leading to a condition of calcium overload that may explain why the $\mathrm{Ca}^{2+}$-mediated neuroprotection of SOD1 cannot be effective in this situation [75].

In order to further demonstrate the SOD1 neuroprotective function in MCM, we tried to perform an siRNA knockdown of its expression, but we only obtained a decrease that was not sufficient to reduce the MCM neuroprotection. This is not surprising as cultured microglia are obtained from mixed glial primary cultures and, once detached, microglial cells are able to maintain their phenotypic features and to be healthy for not more than $48 \mathrm{~h}$ in a serum-free medium like the one we use for MCM. In contrast, it has been previously demonstrated that siRNA knockdown needs more time to completely 
silence the expression of the target gene, i.e. at least $4 / 5$ days after transfection [76-78], a timing that is not compatible with our experimental system. Thus, either a slight decrease in SOD1 expression through partial silencing or an increase through transfection with plasmids expressing human wild-type SOD1 (see above) does not show any change in MCM neuroprotection. Therefore, we used SOD1 inhibitors interfering either directly with $\mathrm{Cu}^{2+}$ bound to the enzyme [43] or indirectly through the action on the $\mathrm{Cu}^{2+}$ chaperon protein [44] to abrogate both the neuroprotective effect of SOD1 exogenously added to a nonconditioned medium or endogenously present in the conditioned medium. By decreasing the $\mathrm{Cu}^{2+}$ loading on SOD1, these inhibitors not only interfere with its enzymatic activity but also affect SOD1 structure and dimerization [79]. As a result, in agreement with the lack of an SOD1 mimetic neuroprotective effect, the inhibitor-mediated reduction of both exogenous SOD1 and MCM neuroprotection could be determined by a possible change in SOD1 structure due to $\mathrm{Cu}^{2+}$ chelation and by the consequent alteration of SOD1 interactions with receptors [45-47].

In conclusion, the present results identify SOD1 as a potential neuroprotective molecule produced and secreted by microglia. Relevant to the present model, in which toxicity was delivered to CGNs through the dopaminergic toxin 6-OHDA, are previous results demonstrating that SOD1 gene transfer protects cultured nigral dopaminergic neurons from the same toxin [80]. Experiments could thus be devised in which microglia are forced to overproduce SOD1 to protect nigro-striatal dopaminergic neurons in models of experimental Parkinson-like neurodegeneration. This could be obtained through specific infection of microglia with viral vectors $[8,81]$ and may be translated to therapy by finding ways to stimulate the neuroprotective microglia phenotype in order to increase the constitutive production and release of neuroprotective factors by microglia, including SOD1 [53-57].

Mutations of SOD1 are found in familial cases of ALS and it has been demonstrated that protein mutations in microglia/macrophage cells are directly implicated in the disease [82-85]. Our novel evidence that normal SOD1 is constitutively released by noninflammatory microglia and protects neurons may be relevant to better understanding the pathogenic/protective role of this protein, as well as of its release by microglia in ALS. A recent study showed that, in SOD1-related ALS mice, repopulation of the brain with microglia not expressing the pathogenic form of mutated SOD1 slowed down motor neuron de- generation and prolonged lifespan [82]. It is equally interesting that intraspinal infusion of wild-type SOD1 in a mouse model of ALS was able to reduce the damage in affected segments of the spinal cord, slow down disease progression, and prolong the lifespan of animals [35]. These data strongly support the hypothesis that, in this neuropathology, there is not only a gain in microglial neurotoxic potential but also a loss of microglia physiological neuroprotective function [86]. In this framework, our preliminary results (see online suppl. fig. 2) obtained by transfecting primary microglia with plasmids expressing either human SOD1 wild-type or the pathogenic G93A mutation which is linked to inherited ALS [24] demonstrate that mutated SOD1 is released by microglia and that the medium conditioned by microglia expressing mutated SOD1 is not neurotoxic by itself, but its neuroprotective activity seems to be partially reduced, at least in this model of neurotoxicity. This is not surprising as it has already been suggested that SOD1 transgenic microglia have a reduced neuroprotective function [87]. However, further experiments must be performed using media conditioned by microglia for different times and by testing these media on different types of neurotoxicity, even in different neuronal types. Therefore, on the basis of our in vitro results and in view of possible therapeutic translations, novel approaches could be devised to test neuroprotection related to microglia-secreted molecules, including SOD1, in animal models of neurodegenerative diseases.

\section{Acknowledgements}

The present work was supported by a young investigator grant of the University of Bologna for strategic research to B.M. and M.C. The authors are grateful to Prof. Contestabile for critically reading the manuscript and to Prof. Stefano Ferroni for his technical assistance with the microfluorometric analysis of intracellular calcium dynamics. The skilful technical assistance of Miss Monia Bentivogli is gratefully acknowledged.

References

Polazzi E, Contestabile A: Reciprocal interactions between microglia and neurons: from survival to neuropathology. Rev Neurosci 2002;13:221-242.

-2 Butovsky O, Koronyo-Hamaoui M, Kunis G, Ophir E, Landa G, Cohen H, Schwartz M: Glatiramer acetate fights against Alzheimer's disease by inducing dendritic-like microglia expressing insulin-like growth factor 1. Proc Natl Acad Sci USA 2006;103:1178411789. 
-3 Schwartz M, Butovsky O, Bruck W, Hanisch UK: Microglial phenotype: is the commitment reversible? Trends Neurosci 2006;29: 68-74.

4 Hanisch UK, Kettenmann H: Microglia: active sensor and versatile effector cells in the normal and pathologic brain. Nat Neurosci 2007;10:1387-1394.

5 Napoli I, Neumann H: Microglial clearance function in health and disease. Neuroscience 2009;158:1030-1038.

6 Streit WJ, Xue QS: Life and death of microglia. J Neuroimmune Pharmacol 2009;4:371379.

7 Graeber MB: Changing face of microglia. Science 2010;330:783-788.

8 Polazzi E, Monti B: Microglia and neuroprotection: from in vitro studies to therapeutic applications. Prog Neurobiol 2010;92:293315.

-9 Walton NM, Sutter BM, Laywell ED, Levkoff LH, Kearns SM, Marshall GP 2nd, Scheffler B, Steindler DA: Microglia instruct subventricular zone neurogenesis. Glia 2006;54: 815-825.

10 Schwartz M, Ziv Y: Immunity to self and selfmaintenance: what can tumor immunology teach us about ALS and Alzheimer's disease? Trends Pharmacol Sci 2008;29:287-293.

11 Ekdahl CT, Kokaia Z, Lindvall O: Brain inflammation and adult neurogenesis: the dual role of microglia. Neuroscience 2009;158: 1021-1029.

12 Wake H, Moorhouse AJ, Jinno S, Kohsaka S, Nabekura J: Resting microglia directly monitor the functional state of synapses in vivo and determine the fate of ischemic terminals. J Neurosci 2009;29:3974-3980.

13 Yirmia R, Goshen I: Immune modulation of learning, memory, neural plasticity and neurogenesis. Brain Behav Immun 2011;25:181213.

14 Toku K, Tanaka J, Yano H, Desaki J, Zhang B, Yang L, Ishihara K, Sakanaka M, Maeda $\mathrm{N}$ : Microglial cells prevent nitric oxide-induced neuronal apoptosis in vitro. J Neurosci Res 1998;53:415-425.

15 Park LC, Zhang H, Gibson GE: Co-culture with astrocytes or microglia protects metabolically impaired neurons. Mech Ageing Dev 2001;123:21-27.

16 Polazzi E, Gianni T, Contestabile A: Microglial cells protect cerebellar granule neurons from apoptosis: evidence for reciprocal signaling. Glia 2001;36:271-280.

17 Neumann J, Gunzer M, Gutzeit HO, Ullrich O, Reymann KG, Dinkel K: Microglia provide neuroprotection after ischemia. FASEB J 2006;20:714-716.

18 Nagata K, Takei N, Nakajima K, Saito H, Kohsaka S: Microglial conditioned medium promotes survival and development of cultured mesencephalic neurons from embryonic rat brain. J Neurosci Res 1993;34:357363.
9 Eleuteri S, Polazzi E, Contestabile A: Neuroprotection of microglia conditioned media from apoptotic death induced by staurosporine and glutamate in cultures of rat cerebellar granule cells. Neurosci Lett 2008;448: 74-78.

20 Qin S, Colin C, Hinners I, Gervais A, Cheret C, Mallat M: System Xc- and apolipoprotein E expressed by microglia have opposite effects on the neurotoxicity of amyloid-beta peptide 1-40. J Neurosci 2006;26:33453356.

21 Nakajima K, Nagata K, Kohsaka S: Plasminogen mediates an interaction between microglia and dopaminergic neurons. Eur Neurol 1994;34:10-16.

22 Polazzi E, Altamira LE, Eleuteri S, Barbaro R, Casadio C, Contestabile A, Monti B: Neuroprotection of microglial conditioned medium on 6-hydroxydopamine-induced neuronal death: role of transforming growth factor beta-2. J Neurochem 2009;110:545-556.

23 Minghetti L, Ajmone-Cat MA, De Berardinis MA, De Simone R: Microglial activation in chronic neurodegenerative diseases: roles of apoptotic neurons and chronic stimulation. Brain Res Brain Res Rev 2005;48:251-256.

24 Valentine JS, Doucette PA, Zittin Potter $S$ : Copper-zinc superoxide dismutase and amyotrophic lateral sclerosis. Annu Rev Biochem 2005;74:563-598.

25 Tortarolo M, Crossthwaite AJ, Conforti L, Spencer JP, Williams RJ, Bendotti C, Rattray M: Expression of SOD1 G93A or wild-type SOD1 in primary cultures of astrocytes down-regulates the glutamate transporter GLT-1: lack of involvement of oxidative stress. J Neurochem 2004;88:481-493.

26 Gallo V, Kingsbury A, Balázs R, Jørgensen OS: The role of depolarization in the survival and differentiation of cerebellar granule cells in culture. J Neurosci 1987;7:2203-2213.

27 Hansen MB, Nielsen SE, Berg K: Re-examination and further development of a precise and rapid dye method for measuring cell growth/cell kill. J Immunol Methods 1998; 119:203-210.

28 Benfenati V, Caprini M, Dovizio M, Mylonakou MN, Ferroni S, Ottersen O, AmiryMoghaddam M: TRPV4 and AQP4 interact to activate regulatory volume decrease in astroglial cells. Proc Natl Acad Sci USA 2011; 108:2563-2568.

29 Grynkiewicz G, Poenie M, Tsien RY: A new generation of $\mathrm{Ca}^{2+}$ indicators with greatly improved fluorescence properties. J Biol Chem 1985;260:3440-3450.

30 Monti B, Polazzi E, Batti L, Crochemore C, Virgili M, Contestabile A: Alpha-synuclein protects cerebellar granule neurons against 6-hydroxydopamine-induced death. J Neurochem 2007;103:518-530.

- 31 Mondola P, Annella T, Santillo M, Santangelo F: Evidence for secretion of cytosolic CuZn superoxide dismutase by Hep G2 cells and human fibroblasts. Int J Biochem Cell Biol 1996;28:677-681.
32 Mondola P, Annella T, Serù R, Santangelo F, Iossa S, Gioielli A, Santillo M: Secretion and increase of intracellular CuZn superoxide dismutase content in human neuroblastoma SK-N-BE cells subjected to oxidative stress. Brain Res Bull 1998;45:517-520.

33 Cimini V, Ruggiero G, Buonomo T, Seru R, Sciorio S, Zanzi C, Santangelo F, Mondola P: $\mathrm{CuZn}$-superoxide dismutase in human thymus: immunocytochemical localisation and secretion in thymus-derived epithelial and fibroblast cell lines. Histochem Cell Biol 2002;118:163-169.

34 Mondola P, Ruggiero G, Serù R, Damiano S, Grimaldi S, Garbi C, Monda M, Greco D, Santillo M: The CuZn superoxide dismutase in neuroblastoma SK-N-BE cells is exported by a microvesicles dependent pathway. Brain Res Mol Brain Res 2003;110:45-51.

35 Turner BJ, Atkin JD, Farg MA, Zang DW Rembach A, Lopes EC, Patch JD, Hill AF, Cheema SS: Impaired extracellular secretion of mutant superoxide dismutase 1 associates with neurotoxicity in familial amyotrophic lateral sclerosis. J Neurosci 2005;25:108-117.

36 Santillo M, Secondo A, Serù R, Damiano S, Garbi C, Taverna E, Rosa P, Giovedì S, Benfenati F, Mondola P: Evidence of calciumand SNARE-dependent release of CuZn superoxide dismutase from rat pituitary $\mathrm{GH} 3$ cells and synaptosomes in response to depolarization. J Neurochem 2007;102:679-685.

37 Bianco F, Pravettoni E, Colombo A, Schenk U, Möller T, Matteoli M, Verderio C: Astrocyte-derived ATP induces vesicle shedding and IL-1 beta release from microglia. J Immunol 2005;174:7268-7277.

38 Takenouchi T, Nakai M, Iwamaru Y, Sugama S, Tsukimoto M, Fujita M, Wei J, Sekigawa A, Sato M, Kojima S, Kitani H, Hashimoto M: The activation of $\mathrm{P} 2 \mathrm{X} 7$ receptor impairs lysosomal functions and stimulates the release of autophagolysosomes in microglial cells. J Immunol 2009;182:2051-2062.

39 Persson T, Calafat J, Janssen H, Karawajczyk M, Carlsson SR, Egesten A: Specific granules of human eosinophils have lysosomal characteristics: presence of lysosome-associated membrane proteins and acidification upon cellular activation. Biochem Biophys Res Commun 2002;291:844-854.

40 Heikkila RE, Cabbat FS: The stimulation of 6-hydroxydopamine autoxidation by bivalent copper: potential importance in the neurotoxic process. Life Sci 1978;23:33-38.

$\checkmark 41$ Tiffany-Castiglioni E, Saneto RP, Proctor $\mathrm{PH}$, Perez-Polo JR: Participation of active oxygen species in 6-hydroxydopamine toxicity to a human neuroblastoma cell line. Biochem Pharmacol 1982;31:181-188.

42 Juarez JC, Betancourt O Jr, Pirie-Shepherd SR, Guan X, Price ML, Shaw DE, Mazar AP, Doñate F: Copper binding by tetrathiomolybdate attenuates angiogenesis and tumor cell proliferation through the inhibition of superoxide dismutase 1. Clin Cancer Res 2006;12:4974-4982. 
-43 Forman HJ, York JL, Fisher AB: Mechanism for the potentiation of oxygen toxicity by disulfiram. J Pharmacol Exp Ther 1980;212: 452-455.

-44 Ogra Y, Komada Y, Suzuki KT: Comparative mechanism and toxicity of tetra- and dithiomolybdates in the removal of copper. J Inorg Biochem 1999;75:199-204.

45 Mondola P, Santillo M, Serù R, Damiano S, Alvino C, Ruggiero G, Formisano P, Terrazzano G, Secondo A, Annunziato L: CuZn superoxide dismutase increases intracellular calcium levels via a phospholipase C-protein kinase C pathway in SK-N-BE neuroblastoma cells. Biochem Biophys Res Commun 2004;324:887-892.

-46 Mondola P, Santillo M, Santangelo F, Garbi C, Daniele A: The calf superoxide dismutase receptor of rat hepatocytes. Comp Biochem Physiol Biochem Mol Biol 1994;108:309-313.

$\checkmark 47$ Secondo A, De Mizio M, Zirpoli L, Santillo $\mathrm{M}$, Mondola P: The CuZn superoxide dismutase (SOD1) inhibits ERK phosphorylation by muscarinic receptor modulation in rat pituitary GH3 cells. Biochem Biophys Res Commun 2008;376:143-147.

48 Ye M, English AM: Binding of polyaminocarboxylate chelators to the active-site copper inhibits the GSNO-reductase activity but not the superoxide dismutase activity of $\mathrm{CuZn}$-superoxide dismutase. Biochemistry 2006;45:12723-12732.

49 Marklund SL: Expression of extracellular superoxide dismutase by human cell lines. Biochem J 1990;266:213-219.

50 Marklund SL: Regulation by cytokines of extracellular superoxide dismutase and other superoxide dismutase isoenzymes in fibroblasts. J Biol Chem 1992;267:6696-6701.

- 51 Glanzer JG, Enose Y, Wang T, Kadiu I, Gong N, Rozek W, Liu J, Schlautman JD, Ciborowski PS, Thomas MP, Gendelman HE: Genomic and proteomic microglial profiling: pathways for neuroprotective inflammatory responses following nerve fragment clearance and activation. J Neurochem 2007; 102:627-645.

-52 Liu J, Hong Z, Ding J, Liu J, Zhang J, Chen S: Predominant release of lysosomal enzymes by newborn rat microglia after LPS treatment revealed by proteomic studies. J Proteome Res 2008; 7:2033-2049.

53 Reynolds AD, Stone DK, Mosley RL, Gendelman HE: Proteomic studies of nitrated alpha-synuclein microglia regulation by CD4+CD25+ T cells. J Proteome Res 2009;8: 3497-3511.

54 Zhou Y, Wang Y, Kovacs M, Jin J, Zhang J: Microglial activation induced by neurodegeneration: a proteomic analysis. Mol Cell Proteomics 2005;4:1471-1479.

55 Lockhart BP, Benicourt C, Junien JL, Privat A: Inhibitors of free radical formation fail to attenuate direct beta-amyloid25-35 peptidemediated neurotoxicity in rat hippocampal cultures. J Neurosci Res 1994;39:494-505.
6 Gunasekar PG, Kanthasamy AG, Borowitz JL, Isom GE: NMDA receptor activation produces concurrent generation of nitric oxide and reactive oxygen species: implication for cell death. J Neurochem 1995;65:2016-2021.

57 Atlante A, Gagliardi S, Minervini GM, Ciotti MT, Marra E, Calissano P: Glutamate neurotoxicity in rat cerebellar granule cells: a major role for xanthine oxidase in oxygen radical formation. J Neurochem 1997;68: 2038-2045.

58 Martín-Romero FJ, García-Martín E, Gutiérrez-Merino C: Inhibition of oxidative stress produced by plasma membrane $\mathrm{NADH}$ oxidase delays low-potassium-induced apoptosis of cerebellar granule cells. J Neurochem 2002;82:705-715.

59 Fatokun AA, Stone TW, Smith RA: Hydrogen peroxide mediates damage by xanthine and xanthine oxidase in cerebellar granule neuronal cultures. Neurosci Lett 2007;416: 34-38.

60 Fatokun AA, Stone TW, Smith RA: Prolonged exposures of cerebellar granule neurons to $\mathrm{S}$-nitroso- $\mathrm{N}$-acetylpenicillamine (SNAP) induce neuronal damage independently of peroxynitrite. Brain Res 2008;1230: 265-272.

61 Al-Gonaiah M, Smith RA, Stone TW: Xanthine oxidase-induced neuronal death via the oxidation of NADH: prevention by micromolar EDTA. Brain Res 2009;1280:33-42.

62 Butovsky O, Koronyo-Hamaoui M, Kunis G, Ophir E, Landa G, Cohen H, Schwartz M: Glatiramer acetate fights against Alzheimer's disease by inducing dendritic-like microglia expressing insulin-like growth factor 1. Proc Natl Acad Sci USA 2006;103:1178411789.

63 Bakalash S, Shlomo GB, Aloni E, Shaked I, Wheeler L, Ofri R, Schwartz M: T-cell-based vaccination for morphological and functional neuroprotection in a rat model of chronically elevated intraocular pressure. J Mol Med 2005;83:904-916.

64 Schwartz M, Kipnis J: A common vaccine for fighting neurodegenerative disorders: recharging immunity for homeostasis. Trends Pharmacol Sci 2004;25:407-412.

65 Angelov DN, Waibel S, Guntinas-Lichius O, Lenzen M, Neiss WF, Tomov TL, Yoles E, Kipnis J, Schori H, Reute A, Ludolph A, Schwartz M: Therapeutic vaccine for acute and chronic motor neuron diseases: implications for amyotrophic lateral sclerosis. Proc Natl Acad Sci USA 2003;100:4790-4795.

66 Haney MJ, Zhao Y, Li S, Higginbotham SM, Booth SL, Han HY, Vetro JA, Mosley RL, Kabanov AV, Gendelman HE, Batrakova EV: Cell-mediated transfer of catalase nanoparticles from macrophages to brain endothelial, glial and neuronal cells. Nanomedicine (Lond) 2011;6:1215-1230.

67 Krieglstein K, Strelau J, Schober A, Sullivan A, Unsicker K: TGF-beta and the regulation of neuron survival and death. J Physiol Paris 2002;96:25-30.
68 Liang J, Takeuchi H, Jin S, Noda M, Li H, Doi Y, Kawanokuchi J, Sonobe Y, Mizuno T, Suzumura A: Glutamate induces neurotrophic factor production from microglia via protein kinase C pathway. Brain Res 2010;1322: $8-23$.

69 Magnus T, Chan A, Grauer O, Toyka KV, Gold R: Microglial phagocytosis of apoptotic inflammatory $\mathrm{T}$ cells leads to down-regulation of microglial immune activation. J Immunol 2001;167:5004-5010.

70 Zelko IN, Mariani TJ, Folz RJ: Superoxide dismutase multigene family: a comparison of the CuZn-SOD (SOD1), Mn-SOD (SOD2), and EC-SOD (SOD3) gene structures, evolution, and expression. Free Radic Biol Med 2002;33:337-349.

71 Chen X, Choi IY, Chang TS, Noh YH, Shin CY, Wu CF, Ko KH, Kim WK: Pretreatment with interferon-gamma protects microglia from oxidative stress via up-regulation of Mn-SOD. Free Radic Biol Med 2009;46: 1204-1210.

72 Inoue K: Purinergic systems in microglia. Cell Mol Life Sci 2008;65:3074-3080.

73 Gyoneva S, Orr AG, Traynelis SF: Differential regulation of microglial motility by ATP/ ADP and adenosine. Parkinsonism Relat Disord 2009;15(suppl 3):S195-S199.

74 Nakanishi S, Okazawa M: Membrane potential-regulated $\mathrm{Ca}^{2+}$ signalling in development and maturation of mammalian cerebellar granule cells. J Physiol 2006;575:389395.

75 Nicholls DG, Budd SL: Mitochondria and neuronal glutamate excitotoxicity. Biochim Biophys Acta 1998;1366:97-112.

76 Choi I, Cho BR, Kim D, Miyagawa S, Kubo T, Kim JY, Park CG, Hwang WS, Lee JS, Ahn C: Choice of the adequate detection time for the accurate evaluation of the efficiency of siRNA-induced gene silencing. J Biotechnol 2005;120:251-261.

77 De Simone R, Niturad CE, De Nuccio C, Ajmone-Cat MA, Visentin S, Minghetti L: TGF- $\beta$ and LPS modulate ADP-induced migration of microglial cells through P2Y1 and P2Y12 receptor expression. J Neurochem 2010;115:450-459.

78 Gao Q, Lu J, Huo Y, Baby N, Ling EA, Dheen ST: NG2, a member of chondroitin sulfate proteoglycans family mediates the inflammatory response of activated microglia. Neuroscience 2010;165:386-394.

79 Ding F, Dokholyan NV: Dynamical roles of metal ions and the disulfide bond in $\mathrm{CuZn}$ superoxide dismutase folding and aggregation. Proc Natl Acad Sci USA 2008; 105: 19696-19701.

80 Barkats M, Millecamps S, Bilang-Bleuel A, Mallet J: Neuronal transfer of the human $\mathrm{CuZn}$ superoxide dismutase gene increases the resistance of dopaminergic neurons to 6-hydroxydopamine. J Neurochem 2002;82: 101-109. 
81 Björklund T, Kirik D: Scientific rationale for the development of gene therapy strategies for Parkinson's disease. Biochim Biophys Acta 2009; 1792:703-713.

-82 Beers DR, Henkel JS, Xiao Q, Zhao W, Wang J, Yen AA, Siklos L, McKercher SR, Appel SH: Wild-type microglia extend survival in PU.1 knockout mice with familial amyotrophic lateral sclerosis. Proc Natl Acad Sci USA 2006;103:16021-16026.
83 Boillee S, Yamanaka K, Lobsiger CS, Copeland NG, Jenkins NA, Kassiotis G, Kollias G, Cleveland DW: Onset and progression in inherited ALS determined by motor neurons and microglia. Science 2006;312:1389-1392.

84 Boillée S, Cleveland DW: Revisiting oxidative damage in ALS: microglia, Nox, and mutant SOD1. J Clin Invest 2008;118:474-478.

85 Henkel JS, Beers DR, Zhao W, Appel SH: Microglia in ALS: the good, the bad, and the resting. J Neuroimmune Pharmacol 2009;4: 389-398.
86 Appel SH, Zhao W, Beers DR, Henkel JS: The microglial-motoneuron dialogue in ALS. Acta Myol 2011;30:4-8.

-87 Sargsyan SA, Blackburn DJ, Barber SC, Grosskreutz J, De Vos KJ, Monk PN, Shaw PJ: A comparison of in vitro properties of resting SOD1 transgenic microglia reveals evidence of reduced neuroprotective function. BMC Neurosci 2011;12:91. 